University of Nebraska - Lincoln

DigitalCommons@University of Nebraska - Lincoln

Biological Systems Engineering: Papers and

Publications

Biological Systems Engineering

2005

\title{
Finite Element Modeling and Experimental Validation of Cooling Rates of Large Ready-to-Eat Meat Products in Small Meat- Processing Facilities
}

\author{
A. Amézquita \\ University of Nebraska-Lincoln \\ L. Wang \\ University of Nebraska-Lincoln \\ Curtis L. Weller \\ University of Nebraska-Lincoln, cweller1@unl.edu
}

Follow this and additional works at: https://digitalcommons.unl.edu/biosysengfacpub

Part of the Biological Engineering Commons

Amézquita, A.; Wang, L.; and Weller, Curtis L., "Finite Element Modeling and Experimental Validation of Cooling Rates of Large Ready-to-Eat Meat Products in Small Meat-Processing Facilities" (2005).

Biological Systems Engineering: Papers and Publications. 97.

https://digitalcommons.unl.edu/biosysengfacpub/97

This Article is brought to you for free and open access by the Biological Systems Engineering at DigitalCommons@University of Nebraska - Lincoln. It has been accepted for inclusion in Biological Systems Engineering: Papers and Publications by an authorized administrator of DigitalCommons@University of Nebraska Lincoln. 


\title{
Finite Element Modeling and Experimental Validation of Cooling Rates of Large Ready-to-Eat Meat Products in Small Meat-Processing Facilities
}

\author{
A. Amézquita, L. Wang, C. L. Weller
}

\begin{abstract}
A two-dimensional axisymmetric transient heat conduction model was developed to simulate air chilling of large ready-to-eatmeat products of ellipsoidal shape. A finite element scheme, using 1,600 linear triangular elements with 861 nodes, was implemented in Matlab 6.5 to solve the model. The model considered a variable initial temperature distribution and combined convective, radiative, and evaporative boundary conditions. Predicted values agreed well with experimental data collected in actual processing conditions. Validation of model performance resulted in maximum deviations of $2.54^{\circ} \mathrm{C}$ and $0.29 \%$ for temperature and weight loss histories, respectively. The maximum temperature deviation $\left(2.54^{\circ} \mathrm{C}\right)$ occurred at the surface; however, for center temperature, the maximum deviation was lower $\left(1.59^{\circ} \mathrm{C}\right)$. The validated model was used to assess the extent of deviations from stabilization performance standards established by the Food Safety and Inspection Service (FSIS) caused by unexpected equipment failure or electrical power outage. A total of 48 simulations were also carried out to establish critical product sizes and operating conditions for compliance with FSIS performance standards. It was concluded that, for cured meat products, small processors should be able to meet the stabilization requirements for any typical commercially available product size, under all simulated chilling conditions. Conversely, for non-cured meats, products should have a maximum weight of $2.25 \mathrm{~kg}$ (with typical dimensions of: major axis $=21.2 \mathrm{~cm}$, minor axis $=13.9 \mathrm{~cm}$ ) in order to comply with FSIS standards, particularly to meet the criteria of cooling between $54.4^{\circ} \mathrm{C}$ to $26.6^{\circ} \mathrm{C}$. The validated model provides a useful quantitative tool for various food safety applications.
\end{abstract}

Keywords. Air chilling, Finite element analysis, Food safety, Heat transfer, Meat cooling.

$\mathrm{D}$ uring processing of ready-to-eat (RTE) meat products, such as boneless ham, roast beef, and smoked turkey breast, rapid cooling immediately after cooking is a critical step to prevent the potential outgrowth of spore-forming foodborne pathogens that survive the heat treatment. The time-temperature compliance guidelines for chilling of RTE meats issued by the Food Safety and Inspection Service (FSIS) of the USDA recommend that, for cured products (i.e., those with at least $100 \mathrm{ppm}$ ingoing sodium nitrite), the internal temperature should be reduced from $54.4^{\circ} \mathrm{C}$ to $26.6^{\circ} \mathrm{C}$ in less than $5 \mathrm{~h}$, and

Article was submitted for review in May 2004; approved for publication by the Food \& Process Engineering Institute Division of ASAE in November 2004.

Trade names are used solely for the purpose of providing specific information. Mention of a trade name, proprietary product, or company does not constitute a guarantee or warranty of the University of Nebraska-Lincoln and does not imply approval of the named product to the exclusion of other products that may be suitable.

The authors are Alejandro Amézquita, ASAE Member Engineer, Former Graduate Research Assistant, Department of Biological Systems Engineering, University of Nebraska, Lincoln, Nebraska, currently Project Leader, Safety and Environmental Assurance Centre, Unilever R\&D Colworth, Sharnbrook, Bedfordshire, United Kingdom; Lijun Wang, ASAE Member Engineer, Research Assistant Professor, and Curtis L. Weller, ASAE Member Engineer, Professor, Department of Biological Systems Engineering, University of Nebraska, Lincoln, Nebraska. Corresponding author: Curtis L. Weller, Department of Biological Systems Engineering, University of Nebraska, 210 L.W. Chase Hall, Lincoln, Nebraska 68583-0726; phone: 402-472-9337; fax: 402-4726338; e-mail: cweller1@unl.edu. from $26.6^{\circ} \mathrm{C}$ to $7.2^{\circ} \mathrm{C}$ in the next $10 \mathrm{~h}(15 \mathrm{~h}$ total cooling time). For non-cured products, the guidelines recommend that the internal temperature should be reduced from $54.4^{\circ} \mathrm{C}$ to $26.6^{\circ} \mathrm{C}$ in less than $1.5 \mathrm{~h}$, and from $26.6^{\circ} \mathrm{C}$ to $4.4^{\circ} \mathrm{C}$ in the next $5 \mathrm{~h}$ ( $6.5 \mathrm{~h}$ total cooling time). These compliance guidelines are part of the stabilization performance standards for preventing the growth of spore-forming bacteria (USDA, 1999).

In general, air chilling is the most common method for cooling of RTE meats in small meat-processing facilities. Typically, products are removed from the smokehouse once the cooking cycle concludes, after which they are sprayed with tap water for 20 to $30 \mathrm{~min}$, and then placed in the chilling room in the same truck or rack used in the smokehouse. Inside the chilling room, cold airflow is arranged to blow through and over the products. This process involves heat exchange between the product surface and the cold airflow, and heat conduction through the product body. Product size, temperature gradient, and proximate chemical composition (i.e., mainly protein, fat, and moisture percentages) determine the heat conduction rate through the body. Product shape and arrangement in the trucks and the air velocity, air temperature, and relative humidity inside the chilling room control the heat exchange rate between the product surface and the cooling medium (cold air).

Cooling rate of large cooked meats after heat treatment is one of the most critical factors in determining the potential growth rate of spore-forming bacteria. According to FSIS guidelines, the aim is to prevent outgrowth of spores of Clostridium perfringens by more than $1 \log _{10}$ cycle (USDA,

Transactions of the ASAE 
1999). Therefore, in order to ensure safety of large cooked meats during chilling, it is necessary to develop efficient methods to evaluate their cooling rates and temperature histories under various realistic processing scenarios. This information could be used subsequently to evaluate temperature dependency of outgrowth of $C$. perfringens spores during cooling.

Most large, commercially available cooked meats have ellipsoidal shapes, regardless if they are whole-muscle or restructured products. Some of the first recorded attempts to model the cooling rate of large ellipsoidal cooked meats were reported in the literature in the late 1980s (Nolan, 1986, 1987). Those studies were based on analytical solutions of two-dimensional transient heat transfer equations in elliptic coordinates, which involved a large number of assumptions for definition of boundary conditions. Moreover, those models did not consider the effect of evaporative cooling due to mass transfer from the surface and were, consequently, poor at predicting cooling rates during air chilling. More recently, various modeling studies have been reported for ellipsoidal cooked meats where numerical solutions, namely finite element methods, have been used (Wang and Sun, 2002a, 2002b, 2002c). In those studies, more realistic boundary conditions were considered, such as combined heat transfer coefficients (i.e., including natural and forced convection, and radiation) and evaporative cooling effect. However, these studies did not analyze the effect of time-varying environmental conditions, such as varying air temperature and velocity. In practical terms, real air chilling operations are characterized by constantly varying environmental conditions. Therefore, it is necessary to move beyond the modeling approaches previously reported and to develop techniques that consider non-uniform initial temperature distributions and heterogeneous environmental conditions. Moreover, from a food safety standpoint, it would be very beneficial to be able to predict the effect of unforeseen processing scenarios, such as refrigeration equipment malfunction or electrical outage, on the temperature history of cooked meats and meat products during cooling. This situation has been regarded as "cooling deviations" by the FSIS (USDA, 1999), and the negative effect on the safety of the product needs to be assessed.

The objectives of the research reported herein were: (1) to develop a two-dimensional axisymmetric heat transfer model for simulation of air chilling of ellipsoidal cooked meat products, (2) to consider realistic input parameters such as a heterogeneous initial condition and time-varying boundary conditions in the development of the model, (3) to validate the model under actual conditions found in commercial meat-processing facilities, and (4) to evaluate the effect of different cooling scenarios (i.e., different product sizes and environmental conditions) on compliance with FSIS stabilization performance standards.

\section{Mathematical Model \\ GOVERNING EQUATIONS}

Most commercially available large RTE meat products, either whole muscle or restructured ones, have ellipsoidal or cylindrical shapes. The governing equation for heat conduction through a meat body in cylindrical coordinates (without inner heat generation) can be expressed as:

$$
\rho c \frac{\partial T}{\partial t}=\frac{1}{r} \frac{\partial}{\partial r}\left(k r \frac{\partial T}{\partial r}\right)+\frac{1}{r^{2}} \frac{\partial}{\partial \phi}\left(k \frac{\partial T}{\partial \phi}\right)+\frac{\partial}{\partial z}\left(k \frac{\partial T}{\partial z}\right)
$$

Cooked meat products are assumed to be isotropic and heterogeneous, particularly with respect to their thermal properties. Their three-dimensional shapes can be characterized by a symmetric ellipsoid revolving around the axis of symmetry $(z)$. Therefore, heat transfer can be modeled as a two-dimensional, axisymmetric, transient heat conduction problem, where heat transfer in the angular direction $(\phi)$ can be neglected. Equation 1 is consequently reduced to:

$$
r \rho c \frac{\partial T}{\partial t}=\frac{\partial}{\partial r}\left(k r \frac{\partial T}{\partial r}\right)+\frac{\partial}{\partial z}\left(k r \frac{\partial T}{\partial z}\right)
$$

\section{Initial Temperature Distribution}

Under actual processing conditions in small facilities, RTE meat products are showered with tap water immediately after cooking. This is done to lower the surface temperature quickly in order to reduce the weight loss caused by evaporation from the surface. Therefore, product temperature is non-uniform upon entry into the air chilling room, and assuming an initial condition of uniform temperature distribution throughout the domain (a common practice in heat transfer modeling) is not valid in practical terms. Consequently, the initial condition for equation 2 can be expressed as:

$$
\begin{aligned}
& T=T_{0}(r, z) \text { for } 0<r<R \\
& \text { and } 0<r<R \text { at } t=0
\end{aligned}
$$

\section{Boundary Conditions}

At the surface of RTE meat products, during air chilling, heat is removed by a combination of convection, radiation, and evaporation. Thus, the boundary conditions for equation 2 are:

At the axis of symmetry:

$$
\begin{aligned}
& \frac{\partial T}{\partial r}=0 \text { at } r=0 \\
& \frac{\partial T}{\partial z}=0 \text { at } z=0
\end{aligned}
$$

At the surface:

$$
-k\left(\frac{\partial T}{\partial n}\right)=-(k \nabla T) \cdot\{n\}=h\left(T_{s}-T_{a}\right)+q_{v}^{\prime \prime}
$$

The term $q_{v}^{\prime \prime}$ is an imposed heat flux that accounts for the heat removed by the latent heat of evaporation. This term is considered separately as (Chuntranuluck et al., 1998a):

$$
q_{v}^{\prime \prime}=k_{a}^{\prime \prime}\left(a_{w} \cdot p_{s}-R H \cdot p_{a}\right) \lambda_{v}
$$

where the terms $p_{s}$ and $p_{a}$ are the saturation water vapor pressure at the surface and air temperatures, respectively, which can be satisfactorily approximated using the Antoine equation (Chuntranuluck et al., 1998a; Van Ness and Abbott, 1997):

$$
\begin{aligned}
& p=\exp \left(23.4795-\frac{3990.56}{T+233.833}\right) \\
& 0^{\circ} \mathrm{C} \leq T \leq 100^{\circ} \mathrm{C}
\end{aligned}
$$


The value of water activity at the product surface can be taken as $a_{w}=1$, an assumption commonly made in modeling of air chilling of meats (Daudin and Swain, 1990; Wang and Sun, 2002b). Relative humidity values can be determined experimentally.

The latent heat of evaporation $\left(\lambda_{v}\right)$ can be expressed as a function of temperature by regressing $\lambda_{v}$ values tabulated in steam tables in the range of temperatures between $0^{\circ} \mathrm{C}$ and $100^{\circ} \mathrm{C}$ (Geankoplis, 2003) giving:

$$
\begin{aligned}
& \lambda_{v}=-2.5 \times 10^{3} T+2.5 \times 10^{6} \\
& 0^{\circ} \mathrm{C} \leq T \leq 100^{\circ} \mathrm{C}, \quad \mathrm{R}^{2}=1.0
\end{aligned}
$$

In order to combine equation 5 into the surface boundary condition (eq. 4), it is a common practice to use the well-known Lewis relationship, which relates $k^{\prime \prime}{ }_{a}$ and $h_{c}$ (Chuntranuluck et al., 1998a, 1998b, 1998c; Daudin and Swain, 1990; Mallikarjunan and Mittal, 1994; Wang and Sun, 2002a, 2002b, 2002c). The Lewis relationship states that for fully developed turbulent flow, the heat and mass transfer coefficients are in direct proportion to each other. Using the Chilton-Colburn analogy, this proportion can be expressed as (Kuitche et al., 1996a; Moyers and Baldwin, 1997):

$$
\frac{h_{c}}{k_{a}^{\prime \prime}}=c_{a} \frac{M_{a}}{M_{w}} P_{a t m}\left(\frac{S c}{P r}\right)^{2 / 3}
$$

For air-water vapor mixtures, the Lewis relationship will be followed if the thermal and molecular diffusivities are identical, or if $S c=P r$, or $L e=1$ (Treybal, 1980). Therefore, equation 8 can be reduced to (Chuntranuluck et al., 1998a, 1998b, 1998c):

$$
\frac{h_{c}}{k_{a}^{\prime \prime}}=\frac{28.97}{18.02} c_{a} P_{a t m}
$$

The value of $h_{c}$ in equation 9 was taken as the combined convective and radiative heat transfer coefficient $(h)$, as it has been reported previously for air blast chilling of cooked meats (Wang and Sun, 2002a, 2002b).

\section{Heat Transfer Coefficient}

During air chilling of RTE meat products, modeling of the heat transfer coefficient must include convection (both forced and natural) and radiation phenomena (i.e., $h=h_{c}+$ $h_{r}$ ). Consequently, the rate of heat transfer from the products to the cooling medium (air) is a function of the velocity, thermo-physical properties, and temperature of the air, as well as the shape and size of the RTE meats undergoing cooling.

For ellipsoidal shapes, Yovanovich (1987b) proposed the following correlation for natural convection (the characteristic dimension in Yovanovich's correlation is the square root of the surface area, $\sqrt{A_{s}}$ ):

$$
\begin{aligned}
& \left(\sqrt[N u \sqrt{A_{s}}]{n c}=3.470+0.510 R a_{\sqrt[1]{A_{s}}}^{1 / 4}\right. \\
& 0<R a_{\sqrt{A_{s}}}<10^{8}
\end{aligned}
$$

For forced convection, the following correlation was selected (Yovanovich, 1988):

$$
\begin{aligned}
& \left(N u_{\sqrt{A_{s}}}\right)_{f_{c}}= \\
& 2 \sqrt{\pi}+\left(0.150 \pi^{1 / 4} \operatorname{Re}_{\sqrt{A_{s}}}^{1 / 2}+0.350 \operatorname{Re}_{\sqrt{A_{s}}}^{0.566}\right) \operatorname{Pr}^{1 / 3} \\
& 10^{-2}<\operatorname{Re}_{\sqrt{A_{s}}}<10^{5} x \text { and } \operatorname{Pr}=0.71 x
\end{aligned}
$$

Air properties were evaluated at film temperature $\left[T_{f}=\right.$ $\left(T_{s}+T_{a}\right) / 2$ ] from tabulated values (Kays and Crawford, 1993).

To calculate the surface area of RTE meat products, their shape can be approximated to that of prolate ellipsoids, which is in accordance with the axisymmetric nature of the governing equation (eq. 2). In this type of ellipsoidal body, two of the semi-axes (minor) are identical, and the third semi-axis (major) is greater or equal to the other two. Let $a$ be the major semi-axis, and $b$ the two minor semi-axes. The surface area of the RTE meat products can be calculated as follows (Yovanovich, 1987a):

$$
A_{s}=2 \pi b^{2}\left[1+\frac{\sin ^{-1} e}{e \sqrt{1-e^{2}}}\right]
$$

where $e=\sqrt{1-(b / a)^{2}}$

The combined natural and forced convective heat transfer coefficient is calculated using an empirical correlation proposed by Churchill (1977) and used in other studies dealing with cooling of food products (Davey and Pham, 1997; Wang and Sun, 2002a, 2002b, 2002c):

$$
h_{c}=\left(h_{n c}^{3}+h_{f c}^{3}\right)^{1 / 3}
$$

The heat transfer coefficient due to radiation can be calculated using equation 14 (Geankoplis, 2003):

$$
h_{r}=\sigma \varepsilon\left(T_{K, s}+T_{K, a}\right)\left(T_{K, s}^{2}+T_{K, a}^{2}\right)
$$

\section{Thermal Properties of RTE Meats}

Empirical correlations proposed by Choi and Okos (1986) were used to estimate thermal properties of cooked meats. These correlations account for the effects of variable moisture and variable temperature during the chilling process. In order to consider the variability of thermal properties in terms of temperature and time, each property was evaluated at the mass average temperature (Haghighi and Segerlind, 1988; Segerlind, 1984) of each element at each time step. The correlations of Choi and Okos were selected for development of the model because they were validated experimentally, and the maximum relative error between observed and predicted values was $5.32 \%$ (see table 3 in the "Results and Discussion" section).

\section{Finite Element Analysis \\ Finite Element Mesh Generation}

According to the axisymmetric nature of the mathematical formulation (eq. 2), the ellipsoidal shapes describing RTE meat products are symmetric in both axial and radial directions. Linear triangular axisymmetric elements were selected to generate the mesh. A fine mesh, consisting of 


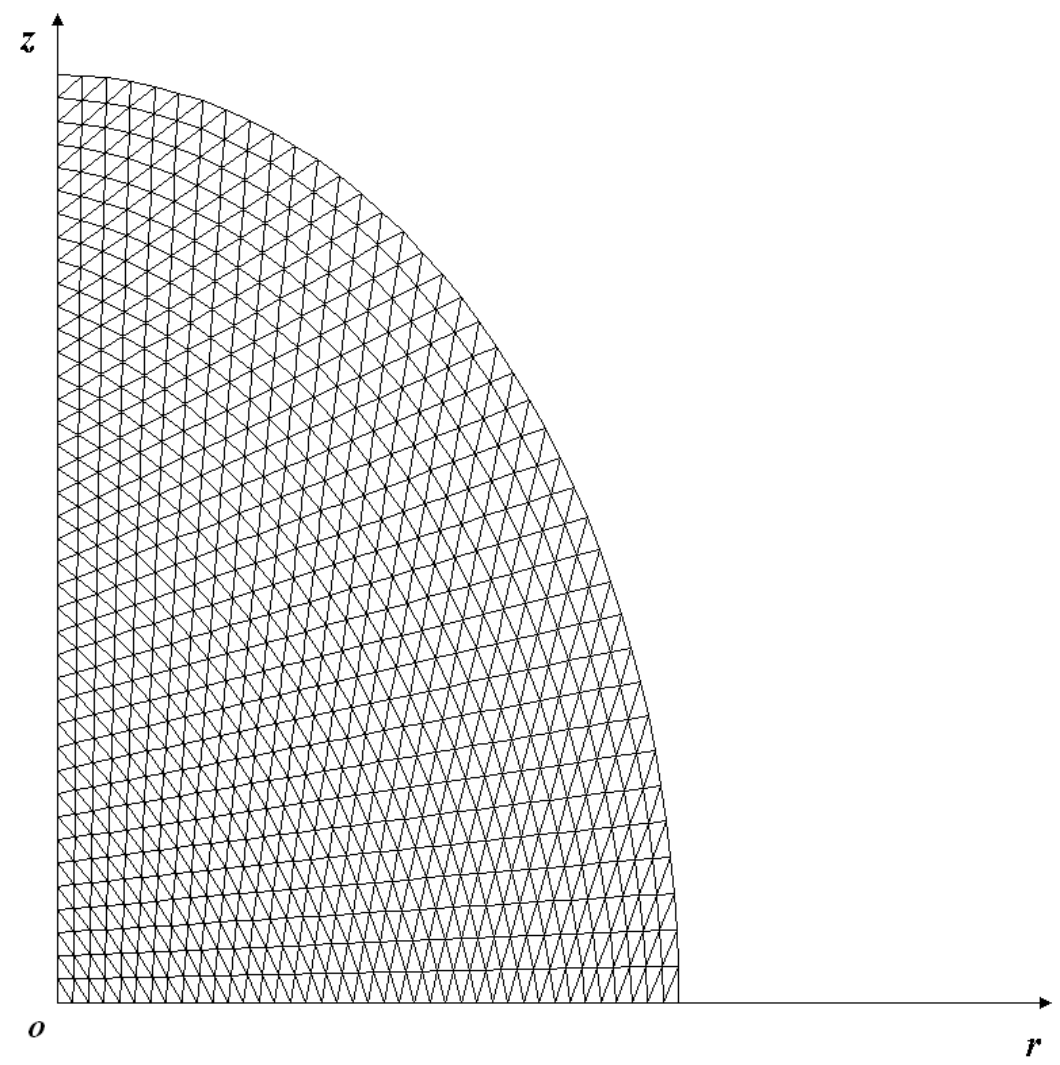

Figure 1. Two-dimensional axisymmetric finite element mesh with linear triangular elements (1,600 elements, 861 nodes).

1,600 elements with 861 nodes $(n)$, was selected to ensure accuracy of the finite element solution (fig. 1).

\section{Finite Element Formulation}

Using the well-known method of weighted residuals or Garlekin's method (Jaluria and Torrance, 2003; Segerlind, 1984), the temperature in each element of the mesh can be approximated with the following linear equation:

$$
\begin{aligned}
T^{e} & =N_{i}(r, z) T_{i}+N_{j}(r, z) T_{j}+N_{k}(r, z) T_{k} \\
& =\left\{N^{e}\right\}\left\{T^{e}\right\}
\end{aligned}
$$

where $N_{i}(r, z), N_{j}(r, z)$, and $N_{k}(r, z)$ are nodal shape functions for each element, and $T_{i}, T_{j}$, and $T_{k}$ are the nodal element temperatures (Haghighi and Segerlind, 1988; Segerlind, 1984).

The finite element formulation reduces equation 2 , a continuous partial differential equation, to a matrix system of ordinary differential equations by assembling the element equations into a global system that can be written in the following general form:

$$
[M]\left\{\frac{\partial \mathrm{T}}{\partial \mathrm{t}}\right\}+[K]\{T\}=\{F\}
$$

where $[M]$ is the global mass matrix $(n \times n),[K]$ is the global stiffness matrix $(n \times n)$, and $\{F\}$ is the global load vector $(n \times$ $1)$.

To obtain the transient response, it is traditional to use finite differences to solve the matrix system presented in equation 16 at each time step. The most commonly used time integration method belongs to the so-called $\theta$ family of approximation (Reddy and Gartling, 1994). Using this method, equation 16 can be re-organized as:

$$
\begin{aligned}
& \left(\frac{1}{\Delta t}[M]+\theta[K]\right)\{T\}_{t+\Delta t}= \\
& \left(\frac{1}{\Delta t}[M]-(1-\theta)[K]\right)\{T\}_{t}+\{F\}_{t}
\end{aligned}
$$

where the parameter $\theta$ is a weighting factor, which varies from 0 to 1 . Depending on the value of $\theta$, the following wellknown time approximation schemes can be obtained: (1) $\theta=$ 0 , forward difference scheme (conditionally stable), (2) $\theta=$ $1 / 2$, Crank-Nicholson scheme (unconditionally stable), (3) $\theta=2 / 3$, Garlekin scheme (unconditionally stable), and (4) $\theta=1$, backward difference scheme (unconditionally stable). In general, for $\theta \geq 1 / 2$, the scheme is unconditionally stable. For the current study, the Crank-Nicholson method was selected because, in addition to being unconditionally stable, the global truncation error is smaller than the errors for the other schemes using the same time step (i.e., Crank-Nicholson is second-order accurate).

To solve the finite element model presented in equation 17, a computer program was written in Matlab 6.5, release 13 (The Mathworks, Inc., Natick, Mass.). The main program assembled the global mass (capacitance) and stiffness (conductance) matrices, and the global load, vector element by element, modified them at appropriate entries for boundary conditions, and solved the matrix system using $L U$ decomposition at each time step. The time step $(\Delta t)$ selected was $10 \mathrm{~s}$, which was considered small enough since total times for typical cooling processes of large cooked meats are at least $12 \mathrm{~h}$. The inputs to the program were the major and minor semi-axes of the ellipsoidal body, the proximate composition (protein, fat, moisture, salt, and carbohydrate 
content) and the initial weight of ham, information about the boundary conditions (air temperature, air velocity, and relative humidity) and information necessary to calculate the initial temperature distribution (initial core and surface temperatures). The program included subroutines for mesh generation, calculation of thermal properties, heat transfer coefficients, heat flux caused by evaporation, and dynamic weight loss. The nodal temperature vector at each time step was stored in a matrix for final output plots of temperature histories and profiles.

\section{Mass Average Temperature}

The concept of mass average temperature (Haghighi and Segerlind, 1988; Segerlind, 1984) was used to estimate the overall ham temperature. This was done for two main reasons: (1) the mass average temperature at each element was used as input value to the Choi and Okos model (1986) to calculate the product thermal properties of each element at each time step, thus increasing the accuracy of predicted values during the simulations, and (2) the overall mass average temperature was used as the main indicator of product temperature history in simulations performed to measure the extent of problems caused by cooling deviations that do not comply with FSIS stabilization requirements.

According to Haghighi and Segerlind (1988), assuming constant density, the mass average temperature of a body is defined by:

$$
\begin{aligned}
\bar{T} & =\left\{\sum _ { e = 1 } ^ { n } \frac { \pi A ^ { e } } { 6 } \left[\left(2 r_{i}+r_{j}+r_{k}\right) T_{i}+\left(r_{i}+2 r_{j}+r_{k}\right) T_{i}\right.\right. \\
& \left.\left.+\left(r_{i}+r_{j}+2 r_{k}\right) T_{i}\right]\right\} \div\left[\sum_{e=1}^{n} \frac{2 \pi A^{e}}{3}\left(r_{i}+r_{j}+r_{k}\right)\right]
\end{aligned}
$$

Equation 18 is only valid for linear axisymmetric triangular elements (Haghighi and Segerlind, 1988; Segerlind, 1984).

\section{Materials and Methods \\ Meat SAMPLeS}

Fully cooked boneless cured ham was used as the model system. Six commercially available, fully cooked ham samples were purchased at local grocery stores for determination of thermal properties and proximate chemical analysis. The six samples were selected such that they would cover a representative population of cooked hams, according to the protein fat free (PFF) percentage requirements established by the FSIS (2002). The distribution of the six samples according to their PFF values was as follows: ham with natural juices (1 sample), ham-water added (2 samples), and ham and water product with $35 \%$ added weight (3 samples). Samples were selected randomly from three purchase locations.

Samples within each PFF category were divided into two sets: one set was sent to the University of Nebraska Meat Chemistry Laboratory for proximate analysis determination (table 1), and the second set used for determination of thermal properties. The results of proximate analysis and thermal properties were compared against the empirical correlations of Choi and Okos (1986) for validation purposes.

\section{DATA ACQUisition AND InSTRUMENTATiON}

A 32-channel data acquisition (DAQ) system controlled by LabVIEW 6.1 software (National Instruments Corporation, Austin, Texas) was used for collection of experimental data necessary for validating the model. The DAQ system consisted of a SCXI-1000 chassis that held a SCXI-1102 32-channel thermocouple amplifier module connected to a SCXI-1303 terminal block. The output signals were transmitted to a laptop computer through a DAQCardAI-16XE-50 card. A program written in LabVIEW 6.1 controlled the DAQ system and recorded the data in real time. The program had a user-friendly interface where the experimenter simply specified the name of the output data storage file and the time interval at which experimental data were to be recorded.

A total of 27 sensors were connected to the 32-channel amplifier module for data collection, including:

- One FMA-904-V air velocity transducer (Omega Engineering, Inc., Stamford, Conn.).

- One HX303V RH/temperature transmitter (Omega)

- One top-loading balance (TR series) for collection of dynamic weight loss data (Denver Instrument Company, Arvada, Colo.).

- Twenty-three type-T thermocouples distributed as follows: a rigid multisensor probe consisting of six thermocouples inside a $3.18 \mathrm{~mm}$ diameter 316 stainless steel sheath (Omega); two flexible multisensor probes consisting of five (IT-17:5) and seven (IT-17:7) thermocouples, respectively, inside a 17 ga Teflon sheath (Physitemp Instruments, Inc., Clifton, N.J.); four TMQSS-062G-6 single thermocouples (Omega); and one MT-23/3 needle probe ( $0.635 \mathrm{~mm}$ diameter) single thermocouple (Physitemp).

The DAQ system, including chassis, thermocouple amplifier module, and laptop computer, was placed in a $56.7 \mathrm{~L}$ plastic tub with latched lid (Rubbermaid, Wooster, Ohio) to make it transportable to meat-processing facilities for data collection.

\begin{tabular}{|c|c|c|c|c|c|c|}
\hline Sample & Commercial Brand & FSIS Category $[\mathrm{b}]$ & $\begin{array}{l}\text { Moisture } \\
\text { (\% w.b.) }\end{array}$ & $\begin{array}{l}\text { Protein } \\
\text { (\% w.b.) }\end{array}$ & $\begin{array}{c}\text { Fat } \\
(\% \text { w.b. })\end{array}$ & $\begin{array}{c}\text { Ash } \\
(\% \text { w.b. })\end{array}$ \\
\hline 1 & Hormel Cure 81 & Ham with natural juices & 73.71 & 18.61 & 4.37 & 3.31 \\
\hline 2 & Cedar Hollow & Ham-water added & 74.68 & 18.50 & 3.57 & 3.25 \\
\hline 3 & Farmland Maple River & Ham-water added & 72.53 & 14.89 & 8.83 & 3.75 \\
\hline 4 & Dubuque & Ham and water product (35\% added weight) & 72.52 & 16.92 & 6.72 & 3.84 \\
\hline 5 & Farmland & Ham and water product ( $35 \%$ added weight) & 71.67 & 16.55 & 7.88 & 3.90 \\
\hline 6 & John Morrell Golden Smoked & Ham and water product ( $35 \%$ added weight) & 74.67 & 16.87 & 4.35 & 4.11 \\
\hline
\end{tabular}

Table 1. Proximate analysis ${ }^{[a]}$ of ham samples used for validation of the empirical correlations of Choi and Okos (1986).

[a] Proximate analyses were determined at the University of Nebraska Meat Chemistry Laboratory.

[b] FSIS (2002). 


\section{INITIAL TEMPERATURE Distribution}

Experimental values of $T_{0}(r, z)$ were measured using temperature-profiling probes consisting of multiple type-T thermocouples spaced at intervals along a sheath (see description in previous section). Two types of custom-made probes were used: one rigid probe (stainless steel sheath), and two flexible ones (Teflon sheath). Thermocouple spacing and probe diameter varied, as illustrated in figure 2 . In the case of the flexible multisensor probes, a pencil-point closed-end needle with a T-handle covered by a hollow stainless steel sheath was used to place them at the desired locations within the hams. Once the probe was placed appropriately, both the needle and stainless steel sheath were slid off the product, leaving only the Teflon surface in contact with the meat. Two multisensor probes were positioned at each of the axes of symmetry. A third multisensor probe was inserted along the same plane and forming a $45^{\circ}$ angle with respect to the other two profiling probes. Additionally, individual thermocouples were inserted at predetermined locations between the center and surface of the hams. A needle probe thermocouple $(0.635 \mathrm{~mm}$ diameter) was used for surface temperature determination by inserting it directly underneath the surface of the hams.

(a)

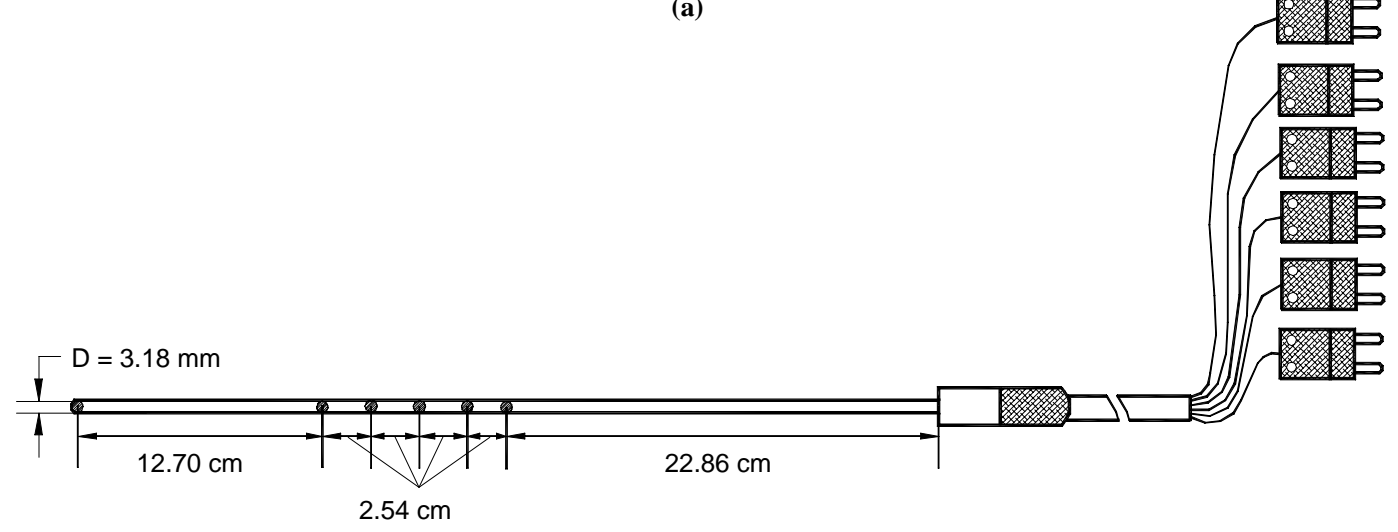

(b)

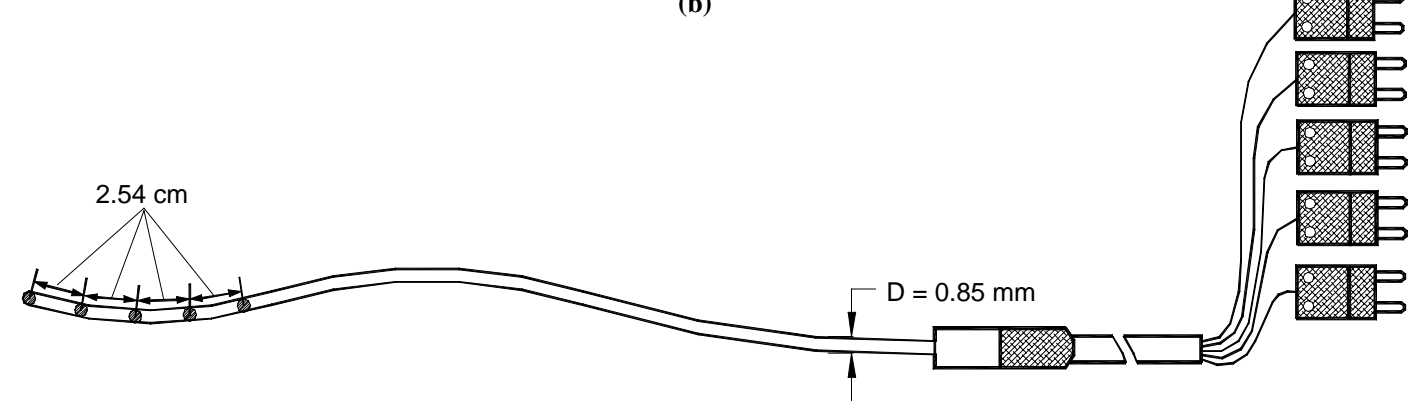

Figure 2. Multisensor temperature-profiling probes used for model validations and determination of initial temperature distribution: (a) rigid probe (stainless steel sheath) with six sensors, and (b) flexible probe (Teflon sheath) with five sensors. A third flexible probe with seven sensors, similar to (b), was also used.

Values of $T_{0}(r, z)$ measured experimentally were fitted to polynomial models based on the least squares estimation (SAS PROC REG) in SAS release 8.2 (SAS Institute, Inc., Cary, N.C.). One polynomial was fitted for each validation experiment. For selection of the best model, both secondand third-order models were evaluated, comparing the models obtained by backward, forward, and stepwise elimination methods. Final model selection was based on three criteria: the value of $\mathrm{R}^{2}$, the value of the residual mean square (MSE), and the Mallows Cp statistic (Draper and Smith, 1998).

\section{Convective Heat Transfer Coefficient}

Convective heat transfer coefficients predicted from empirical correlations (eqs. 10 and 11) were validated experimentally. The methodology has been described previously (Ryland et al., 2004). Briefly, experimental validation was based on: (1) a quasi-steady state method based on the lumped parameter condition concept (Arce and Sweat,
1980; Rahman, 1995), and (2) a method described by Kondjoyan and Daudin (1997) based on constant drying rates of fully wetted bodies.

The first method is valid for materials of high thermal conductivity in order to maintain a low Biot number $(B i<$ 0.1 ). For this purpose, a ham-shaped block of aluminum was used as a theoretical model. The model was milled from a solid block of grade 6061 aluminum at the Department of Biological Systems Engineering's machine shop (University of Nebraska-Lincoln, Lincoln, Neb.). Its shape was modeled after a $2.25 \mathrm{~kg}$ commercial boneless ham. A small hole (3.25 mm diameter) through the center of its length allowed for the placement of the rigid multisensor temperature-profiling probe previously described. The aluminum model was heated up to $80^{\circ} \mathrm{C}$ in an Isotemp oven (Fisher Scientific, Hampton, N.H.) to a center temperature of $71.1^{\circ} \mathrm{C} \pm 1.7^{\circ} \mathrm{C}$. The heated model was then placed immediately in an Aminco-Aire environmental chamber (Parameter Generation and Control, Inc., Black Mountain, N.C.), where a 
continuous flow of cold air $\left(T_{a}=6.5^{\circ} \mathrm{C} \pm 0.3^{\circ} \mathrm{C}\right)$ was directed around the aluminum model. Temperature data were recorded every $30 \mathrm{~s}$ using the DAQ system described previously. Values of $h_{c}$ were obtained by non-linear regression (SAS PROC NLIN) in SAS release 8.2 (SAS Institute, Inc., Cary, N.C.) using the Marquardt updating formula. The non-linear model used was that corresponding to the lumped parameter condition as shown in equation 19:

$$
T=T_{a}+\left(T_{0}-T_{a}\right) \exp \left(-\frac{h_{c} A_{s}}{m_{\text {alum }} c_{\text {alum }}} t\right)
$$

The second method consisted of drying a fully wetted body in an air current with constant properties. The heat transfer coefficient was determined during the constant drying-rate period using the equations described by Kondjoyan and Daudin (1997). For that purpose, the aluminum ham model was wrapped in strips of newspaper and then coated with a $5 \mathrm{~mm}$ thick layer of plaster of Paris and fully wetted in water overnight. Subsequently, the wetted model was placed on a top-loading balance inside the environmental chamber described previously with a continuous flow of air directed around the plaster-covered model. The balance was connected to the DAQ system, and dynamic weight loss was recorded every $30 \mathrm{~s}$. The slope of the plot of weight loss vs. time during the constant-rate period was used for calculations.

\section{Thermal Properties}

Thermal conductivity, thermal diffusivity, and specific heat for each of the six commercial ham samples were determined within a temperature range pertinent to air-chilling processes $\left(4^{\circ} \mathrm{C}\right.$ to $\left.80^{\circ} \mathrm{C}\right)$. Methods for measurement of each property are described below.

\section{Thermal Conductivity and Thermal Diffusivity}

Ham samples were cut into equal size cylindrical portions (diameter $=3.5 \pm 0.2 \mathrm{~cm}$, height $=6.5 \pm 0.2 \mathrm{~cm}$ ). Controlled temperature chambers were used to bring samples to test temperatures for determining thermal conductivity and diffusivity values. Test temperature values were $4^{\circ} \mathrm{C}, 25^{\circ} \mathrm{C}$, $45^{\circ} \mathrm{C}$, and $65^{\circ} \mathrm{C}$. Five independent replications were carried out at each test temperature.

A KD2 thermal properties analyzer (Decagon Devices, Inc., Pullman, Wash.) was used to determine the thermal conductivity and thermal diffusivity of ham samples. The KD2 analyzer calculates values of thermal conductivity, resistivity, and diffusivity based on the unsteady-state line heat source method (Murakami et al., 1996; Sweat and Haugh, 1974). Before each experiment, calibration of the $\mathrm{KD} 2$ analyzer was verified using glycerin at $17^{\circ} \mathrm{C}$ and distilled water at $18^{\circ} \mathrm{C}$, as recommended by the manufacturer (Fontana et al., 2001).

\section{Specific Heat}

Specific heat of ham samples was determined by differential scanning calorimetry according to ASTM standard E1269-01 (ASTM, 2003). Measurements were carried out using a Pyris 1 differential scanning calorimeter (DSC) equipped with an Intracooler 1P refrigeration unit (PerkinElmer, Inc., Norwalk, Conn.). Nitrogen gas was used to flush the sample holder. The DSC was calibrated using indium. Three individual (25 to $40 \mathrm{mg}$ ) samples of each ham tested were scanned from $10^{\circ} \mathrm{C}$ to $90^{\circ} \mathrm{C}$ at a heating rate of $5^{\circ} \mathrm{C} / \mathrm{min}$ in stainless steel pans (Perkin-Elmer Corp., Norwalk, Conn.) using an empty pan as the reference. Reference pans and sample pans were balanced to within $0.1 \mathrm{mg}$ of each other.

\section{Model Validation and Measure of Performance}

Experimental validation of the model was carried out under actual industrial conditions. A total of six trials in two different meat-processing facilities were performed for experimental data collection (table 2). In all cases, hams were cooked in commercial smokehouses to an internal temperature of $66^{\circ} \mathrm{C}$, after which they were showered with tap water for 20 to $30 \mathrm{~min}$ (time was defined by each facility) inside the smokehouse. Hams were then moved to an air-chilling room on the same trucks in which they were cooked. Upon entry into the chilling room, dimensions (major and minor axes) of a randomly selected ham were recorded. The ham was placed subsequently on a plastic rack previously set up on the top-loading balance and initial weight was recorded. Immediately after weighing, the ham was instrumented with two of the multisensor temperature-profiling probes, each one along the axes of symmetry. A third multisensor probe was inserted along the same plane and forming a $45^{\circ}$ angle with respect to the other two profiling probes. Individual thermocouples were inserted at predetermined locations between center and surface of the ham. Surface temperature was recorded by inserting a needle probe thermocouple (0.635 $\mathrm{mm}$ diameter) directly underneath the ham surface (fig. 3). Air velocity, relative humidity, and air temperature information were also recorded by placing instruments, previously described, on the truck as close to the ham surface as possible. In the case of the air velocity transducer, the sensor (a glass-coated platinum resistance detector) was placed perpendicular to the main airflow direction. Data were recorded every $30 \mathrm{~s}$ until the end of the cooling process (i.e., when ham core temperature reached $4^{\circ} \mathrm{C}$ or below).

As a measure of performance of the model, deviations between the observed and predicted temperature and cumulative weight loss values were calculated as:

Table 2. Chilling room and cooked ham characteristics in two small meat-processing facilities used for validation tests.

\begin{tabular}{|c|c|c|c|c|c|c|c|c|c|c|c|}
\hline \multirow[b]{2}{*}{ Test } & \multirow[b]{2}{*}{ Plant } & \multirow{2}{*}{$\begin{array}{l}\text { Shower } \\
\text { Time } \\
\text { (min) }\end{array}$} & \multicolumn{2}{|c|}{ Dimensions $(\mathrm{cm})$} & \multicolumn{2}{|c|}{ Initial Temperature $^{[a]}$} & \multicolumn{3}{|c|}{ Weight } & \multirow{2}{*}{$\begin{array}{l}\text { Setpoint Air } \\
\text { Temp. } \\
\left({ }^{\circ} \mathrm{C}\right)\end{array}$} & \multirow{2}{*}{$\begin{array}{l}\text { Setpoint Air } \\
\text { Velocity } \\
(\mathrm{m} / \mathrm{s})\end{array}$} \\
\hline & & & $\begin{array}{l}\text { Major } \\
\text { Axis }\end{array}$ & $\begin{array}{l}\text { Minor } \\
\text { Axis }\end{array}$ & $\begin{array}{c}\text { Center } \\
\left({ }^{\circ} \mathrm{C}\right)\end{array}$ & $\begin{array}{c}\text { Surface } \\
\left({ }^{\circ} \mathrm{C}\right)\end{array}$ & $\begin{array}{c}\text { Initial } \\
(\mathrm{kg})\end{array}$ & $\begin{array}{l}\text { Final } \\
(\mathrm{kg})\end{array}$ & $\begin{array}{c}\text { Loss } \\
(\%)\end{array}$ & & \\
\hline 1 & 1 & 20 & 30.0 & 20.0 & 66.3 & 40.4 & 7.07 & 6.76 & 4.39 & 2.5 & 2.0 \\
\hline 2 & 1 & 20 & 26.5 & 19.7 & 66.4 & 28.0 & 6.11 & 5.95 & 2.55 & 2.5 & 2.0 \\
\hline 3 & 1 & 20 & 29.0 & 19.0 & 69.1 & 40.4 & 6.13 & 5.90 & 3.75 & 2.5 & 2.0 \\
\hline 4 & 1 & 20 & 28.5 & 20.0 & 69.7 & 36.4 & 6.80 & 6.46 & 5.03 & 2.5 & 2.0 \\
\hline 5 & 2 & 30 & 21.2 & 13.9 & 63.2 & 32.3 & 2.25 & 2.18 & 2.95 & -3.5 & 2.5 \\
\hline 6 & 2 & 30 & 27.0 & 16.0 & 67.3 & 39.8 & 4.54 & 4.33 & 4.62 & -3.5 & 2.5 \\
\hline
\end{tabular}

[a] Upon entry in the chilling room. 


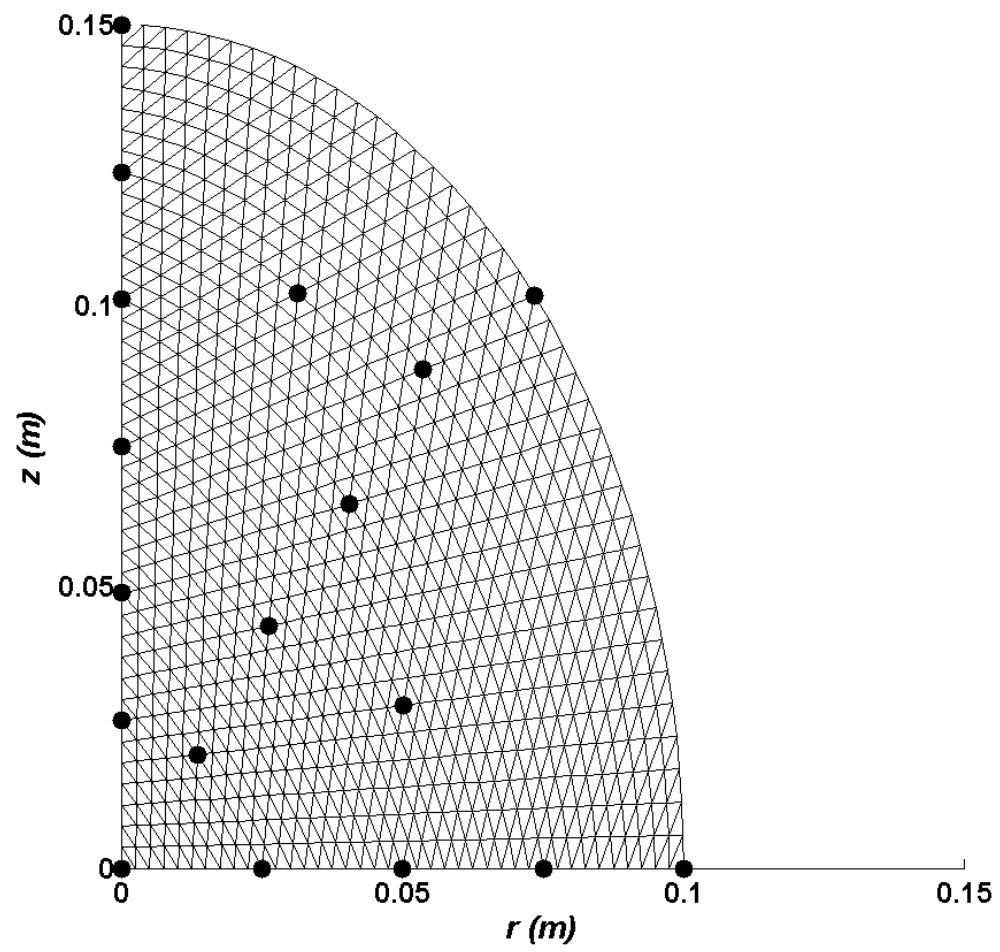

Figure 3. Location of sensors across ham central plane used during validation studies and for establishment of initial temperature distributions.

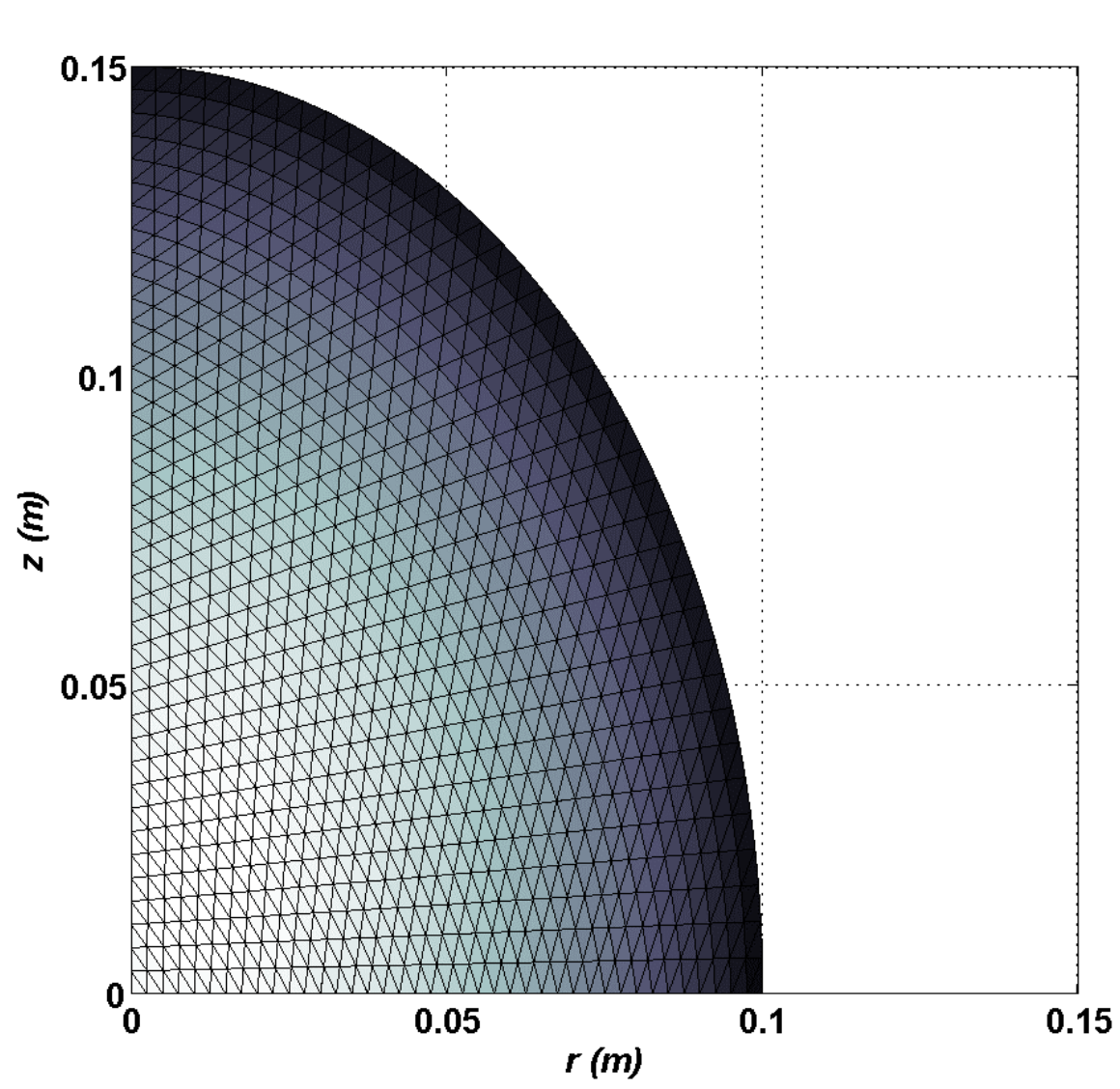

${ }^{\circ} \mathrm{C}$

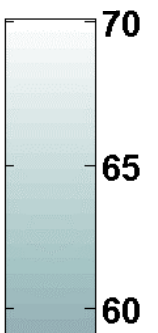

$-55$

50

45

40

0.15

Figure 4. Characteristic initial temperature distribution of cooked hams upon entry into an air-chilling room (two-dimensional representation). 


$$
M P=\sqrt{\frac{\sum_{i=1}^{n^{\prime}}(\text { observed value }- \text { predicted value })^{2}}{n^{\prime}}}
$$

where $M P$ is a measure of performance analogous to the traditional root mean square error. $M P$ had units of ${ }^{\circ} \mathrm{C}$ or $\%$ when the values compared were temperatures or cumulative weight losses, respectively.

\section{Results ANd Discussion}

\section{INITIAL TEMPERATURE DisTRIBUTION}

In general, third-order models gave better fits than second-order models, based on criteria described previously (Amézquita, 2004). Higher-order terms were not tried because the models would become too cumbersome to work with. A graphical representation of a typical initial temperature distribution obtained by the fitted models is presented in figure 4 . As can be observed, the surface temperature was lower than the core temperature at the beginning of the air-chilling process due to the effect of showering. It is also important to note that in four of the six validation studies, temperature values at points around the ham center were greater than or equal to the core temperature upon entry into the chilling room. This was expected in large products, where the cooling rate is controlled by heat conduction due to the low thermal conductivity value of cooked meats. This phenomenon was responsible for the "shoulders" normally observed in $T$ vs. $t$ plots during the first stages of cooling of large cooked meats, in which the core temperature continues to increase temporarily until surrounding points reach a value lower than its initial one.

Studies reported in the literature normally assume that the initial condition is constant (i.e., there is no temperature distribution at $t=0$ ) (Chuntranuluck et al., 1998a; Mallikarjunan and Mittal, 1994; Wang and Sun, 2002a, 2002b). Only a few studies have recognized the importance of considering an initial temperature distribution (Kuitche et al., 1996a, 1996b) to increase the accuracy of the predictions. In the current study, temperature distributions obtained using multiple linear regression provided realistic initial conditions for the mathematical model, thus improving the performance and accuracy of the predictions.

\section{Convective Heat Transfer Coefficient}

For experimental validation of the convective heat transfer coefficient, environmental conditions were maintained constant and at values representative of industrial cooling systems. Average air temperature was $6.5^{\circ} \mathrm{C}$ $\pm 0.3^{\circ} \mathrm{C}$, average air velocity was $1.2 \pm 0.2 \mathrm{~m} / \mathrm{s}$, and average relative humidity was $83 \% \pm 1 \%$ (Ryland et al., 2004).

The quasi-steady state method, based on the lumped parameter approach, resulted in a convective heat transfer coefficient mean value of $5.1 \mathrm{~W} / \mathrm{m}^{2} \mathrm{~K}$, whereas values obtained using the method proposed by Kondjoyan and Daudin (1997), including simultaneous heat and mass transfer, resulted in a mean value of $9.7 \pm 0.4 \mathrm{~W} / \mathrm{m}^{2} \mathrm{~K}$. These values fell within the expected range of 5 to $20 \mathrm{~W} / \mathrm{m}^{2} \mathrm{~K}$ but were lower than those estimated using previously developed empirical correlations.

The quasi-steady state method underestimated $h_{c}$ values, probably because the aluminum model was too large, violating the lumped-parameter condition of a uniform temperature distribution throughout the body. This approach has been used successfully in other meat-processing applications involving smaller products such as hamburgers (Millsap and Marks, 2002). However, for products as large as the $2.25 \mathrm{~kg}$ ham model used in this study, this methodology appeared inadequate.

Conversely, the simultaneous heat and mass transfer approach appeared to be valid, and values of $h_{c}$ obtained with this method resulted in a relative error of only $2.5 \%$ when compared against the empirical correlations used in the present study (eqs. 10 and 11). Kondjoyan and Daudin (1997) reported differences of up to $5 \%$ between theoretical and experimental values when using their proposed methodology. Thus, in our study, the difference observed between experimental and predicted $h_{c}$ values was considered acceptable for modeling purposes.

\section{Ham Thermal Properties}

Experimental values of thermal properties agreed well with predictions obtained using the empirical correlations of Choi and Okos (1986). The maximum relative error (absolute value) between experimental and predicted values was found for the thermal conductivity of sample 2 at $45^{\circ} \mathrm{C}$, with a value of 5.3\% (table 3 ). The correlations of Choi and Okos were consequently implemented in the finite element computer program for estimation of thermal properties, as relative errors lower than $5.3 \%$ were considered acceptable for modeling purposes. These correlations are well established, and they are used commonly in food-processing calculations. In particular, they have been applied successfully in studies dealing with cooling of meats (Mallikarjunan and Mittal, 1994, 1995, 1996).

A summary of experimental results and relative errors is shown in table 3 for four temperature values. Figure 5 presents the results for specific heat determination by differential scanning calorimetry. The DSC peaks around $25^{\circ} \mathrm{C}$ to $28^{\circ} \mathrm{C}$ were more pronounced in samples 2 and 5 . This may have been due to the presence of pork fat, which has a corresponding melting point temperature. This behavior does not have great influence on model performance, as the variation in specific heat values can be considered negligible for the purpose of heat transfer calculations.

\section{Model Validation}

A representative depiction of simulation results at three different locations within a ham is shown in figure 6 . Results shown correspond to validation test 1 , in which a $7.07 \mathrm{~kg}$ ham was used as the experimental sample (table 2). The dimensions of the ham were: major axis $=30 \mathrm{~cm}$, and minor axis $=20 \mathrm{~cm}$. Initial center and surface temperatures were $66.3^{\circ} \mathrm{C}$ and $40.4^{\circ} \mathrm{C}$, respectively. As the validations were performed in real processing situations, the environmental conditions were variable, especially during the first 300 to $450 \mathrm{~min}$ of the cooling process (fig. 7). Time-varying environmental conditions will be discussed later.

As can be observed in figure 6, this particular cooling process met the FSIS stabilization requirements for cured products, since the time from $54.4^{\circ} \mathrm{C}$ to $26.6^{\circ} \mathrm{C}$ was $3.87 \mathrm{~h}$ (232 min), and from $26.6^{\circ} \mathrm{C}$ to $7.2^{\circ} \mathrm{C}$ was $6.33 \mathrm{~h}(380 \mathrm{~min})$, for a total of $10.2 \mathrm{~h}$. It also is important to note that the discrepancies observed between predicted and observed surface temperature values may have resulted from the rapid 
Table 3. Thermal conductivity, specific heat, and thermal diffusivity values at selected temperatures for six commercial cooked ham samples.

\begin{tabular}{|c|c|c|c|c|c|c|c|c|c|c|c|c|}
\hline & \multicolumn{4}{|c|}{$k(\mathrm{~W} / \mathrm{m} \mathrm{K})$} & \multicolumn{4}{|c|}{$c(\mathrm{~J} / \mathrm{kg} \mathrm{K})$} & \multicolumn{4}{|c|}{$\dot{a}\left(\times 10^{-6} \mathrm{~m}^{2} / \mathrm{s}\right)$} \\
\hline & $4^{\circ} \mathrm{C}$ & $25^{\circ} \mathrm{C}$ & $45^{\circ} \mathrm{C}$ & $65^{\circ} \mathrm{C}$ & $10^{\circ} \mathrm{C}$ & $25^{\circ} \mathrm{C}$ & $45^{\circ} \mathrm{C}$ & $65^{\circ} \mathrm{C}$ & $4^{\circ} \mathrm{C}$ & $25^{\circ} \mathrm{C}$ & $45^{\circ} \mathrm{C}$ & $65^{\circ} \mathrm{C}$ \\
\hline \multicolumn{13}{|l|}{ Sample 1} \\
\hline Experimental value & 0.488 & 0.505 & 0.535 & 0.541 & 3502.3 & 3543.6 & 3539.4 & 3557.1 & 0.128 & 0.134 & 0.144 & 0.145 \\
\hline Relative error $(\%)^{[\mathrm{a}]}$ & 1.55 & 3.39 & 1.99 & 3.14 & 2.12 & 1.14 & 1.54 & 1.41 & 1.83 & 2.32 & 0.06 & 1.45 \\
\hline \multicolumn{13}{|l|}{ Sample 2} \\
\hline Experimental value & 0.487 & 0.507 & 0.523 & 0.560 & 3564.2 & 3586.8 & 3642.0 & 3658.0 & 0.128 & 0.134 & 0.137 & 0.146 \\
\hline Relative error $(\%)$ & 2.54 & 4.01 & 5.32 & 0.89 & 0.98 & 0.52 & 0.72 & 0.79 & 1.99 & 3.07 & 4.74 & 1.66 \\
\hline \multicolumn{13}{|l|}{ Sample 3} \\
\hline Experimental value & 0.493 & 0.51 & 0.528 & 0.534 & 3589.0 & 3659.8 & 3664.1 & 3673.9 & 0.131 & 0.134 & 0.139 & 0.141 \\
\hline Relative error (\%) & 1.24 & 0.10 & 0.01 & 0.68 & 1.17 & 2.96 & 2.78 & 2.67 & 0.49 & 2.24 & 2.18 & 2.86 \\
\hline \multicolumn{13}{|l|}{ Sample 4} \\
\hline Experimental value & 0.467 & 0.507 & 0.510 & 0.530 & 3555.0 & 3659.3 & 3611.5 & 3632.5 & 0.125 & 0.133 & 0.136 & 0.141 \\
\hline Relative error (\%) & 4.60 & 1.48 & 4.80 & 2.93 & 0.22 & 2.97 & 1.325 & 1.53 & 3.70 & 3.01 & 5.20 & 3.79 \\
\hline \multicolumn{13}{|l|}{ Sample 5} \\
\hline Experimental value & 0.478 & 0.507 & 0.520 & 0.525 & 3589.0 & 3659.8 & 3664.1 & 3673.9 & 0.128 & 0.132 & 0.136 & 0.138 \\
\hline Relative error $(\%)$ & 1.54 & 0.43 & 1.56 & 2.51 & 1.73 & 3.53 & 3.35 & 3.23 & 1.45 & 3.68 & 4.51 & 5.22 \\
\hline \multicolumn{13}{|l|}{ Sample 6} \\
\hline Experimental value & 0.49 & 0.513 & 0.528 & 0.553 & 3493.0 & 3547.5 & 3587.4 & 3597.7 & 0.129 & 0.138 & 0.140 & 0.147 \\
\hline Relative error $(\%)$ & 1.98 & 2.70 & 4.23 & 1.87 & 2.74 & 1.40 & 0.57 & 0.65 & 1.40 & 0.60 & 3.41 & 0.98 \\
\hline
\end{tabular}

[a] Relative error (in absolute value) of predicted values (using the model of Choi and Okos, 1986).

variations in air temperature, which instantaneously affected the surface temperature. However, from a food safety perspective, modeling of surface temperature histories lacks interest, since the most critical point is the center of the product, which has the smallest cooling rate values.

Figure 7 shows the typical behavior of environmental conditions in the commercial air chilling rooms used in validation studies. In general, air temperature values at the beginning of chilling ranged between $10^{\circ} \mathrm{C}$ and $35^{\circ} \mathrm{C}$. Depending on the capacity of the refrigeration equipment and the total product load entering the room on a particular day, air temperature could take up to $7 \mathrm{~h}$ to reach the setpoint value (table 2). Air velocities were also variable within the expected range for air blast chilling rooms ( 1 to $5 \mathrm{~m} / \mathrm{s})$. The relative humidity remained fairly constant and was above $95 \%$ in all cases. One of the valuable contributions of the current study is the fact that realistic time-varying environ-

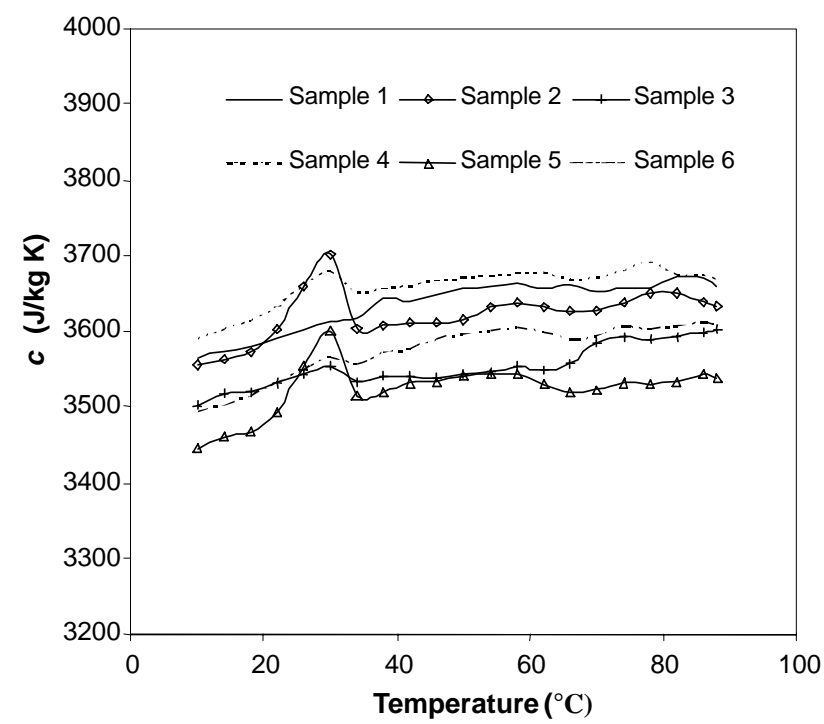

Figure 5. Specific heat of cooked ham samples determined by differential scanning calorimetry per ASTM standard E1269-01 (ASTM, 2003). mental conditions were considered as inputs to the model. Air temperature, air velocity, and relative humidity values collected during validation experiments were arranged as vectors and included in the finite element solution in a stepwise fashion. This provided more realistic results during simulations.

Figure 8 shows the cumulative weight loss for the same validation test. In general, total weight loss during air chilling never exceeded $5 \%$ in all validation experiments. The variability in experimental weight values was originated by circulating air blowing on the top-load scale. In spite of this constantly varying behavior, a general trend was observed in all validations, and there was good general agreement between predicted and experimental data.

Performance of the model was determined by $M P$ values for both temperature and cumulative weight loss predictions. A summary of this performance for all validation experi-

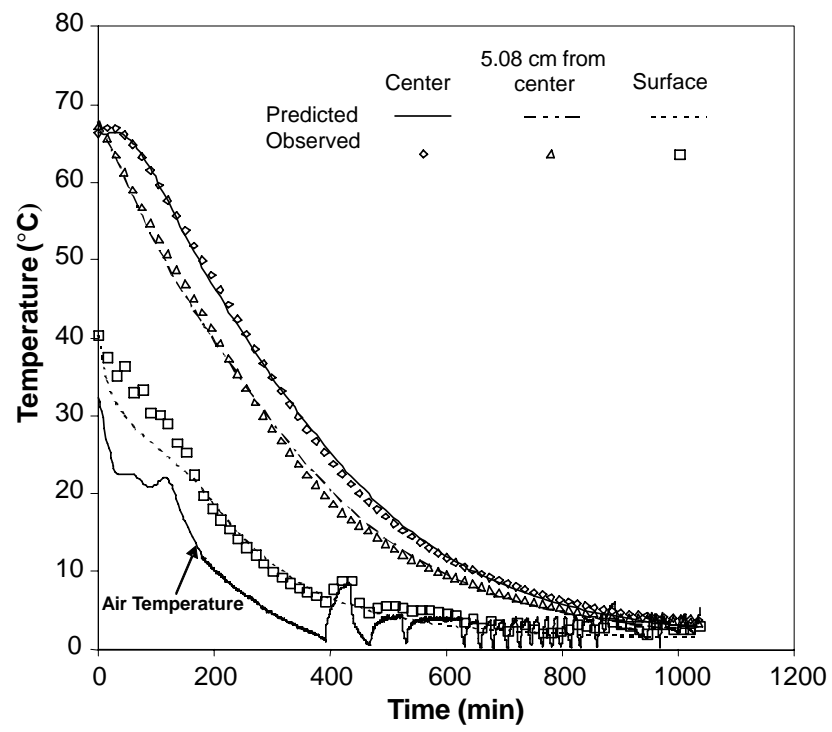

Figure 6. Comparison of observed and predicted temperature histories for validation test 1 (see table 2 for description of validation tests). 


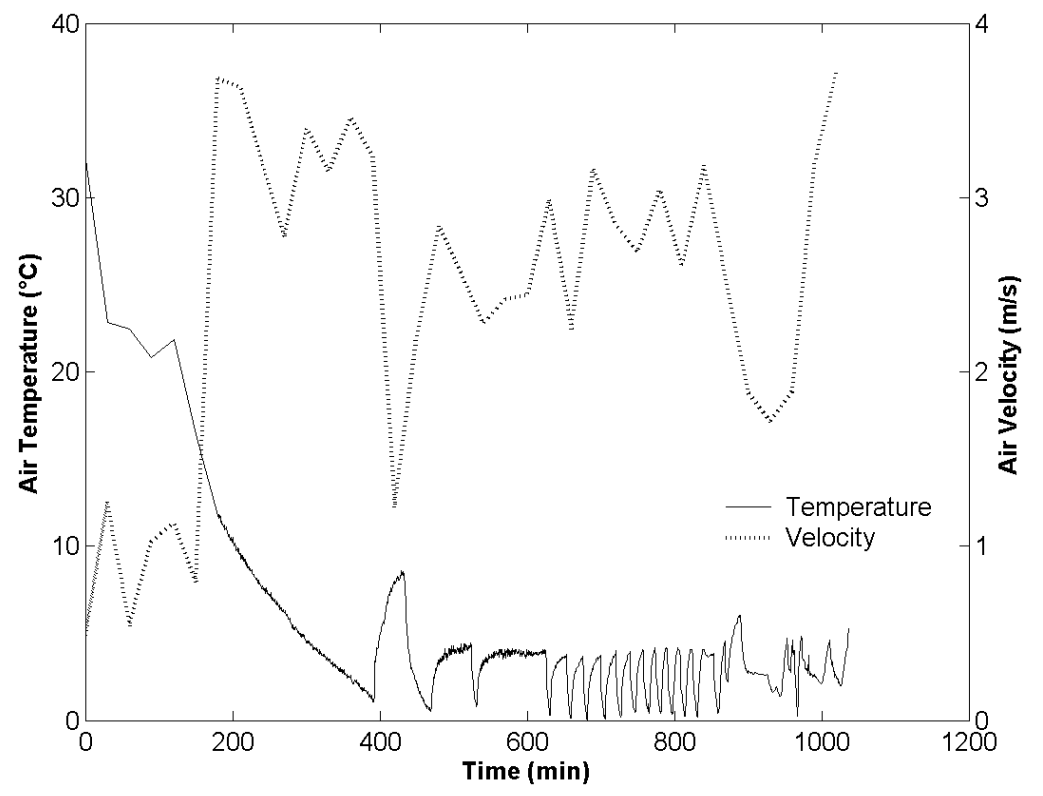

Figure 7. Typical air temperature and air velocity conditions found in commercial air chilling rooms for cooked hams. Data shown correspond to validation test 1 . Relative humidity values are not shown as they were fairly constant and above $95 \%$ in all cases.

ments is presented in table 4. Model performance with respect to temperature was evaluated for three different locations within the hams (i.e., at the center, at $5.08 \mathrm{~cm}$ from the center, and at the surface). As can be observed in table 4, the simulation results were in good agreement with the observed temperature and cumulative weight loss histories. Maximum temperature deviations were obtained for validation tests 4 and $6\left(2.24^{\circ} \mathrm{C}\right.$ and $2.54^{\circ} \mathrm{C}$, respectively) and corresponded to surface temperature values. These discrepancies between observed and predicted values at the surface have been discussed previously. The maximum deviation for center temperature was $1.59^{\circ} \mathrm{C}$ (validation test 6). As for cumulative weight loss deviations, the maximum value of $0.29 \%$ corresponded to validation test 1 and was probably due to the constantly varying experimental data caused by the airflow blowing directly on the top-loading balance. Other sources

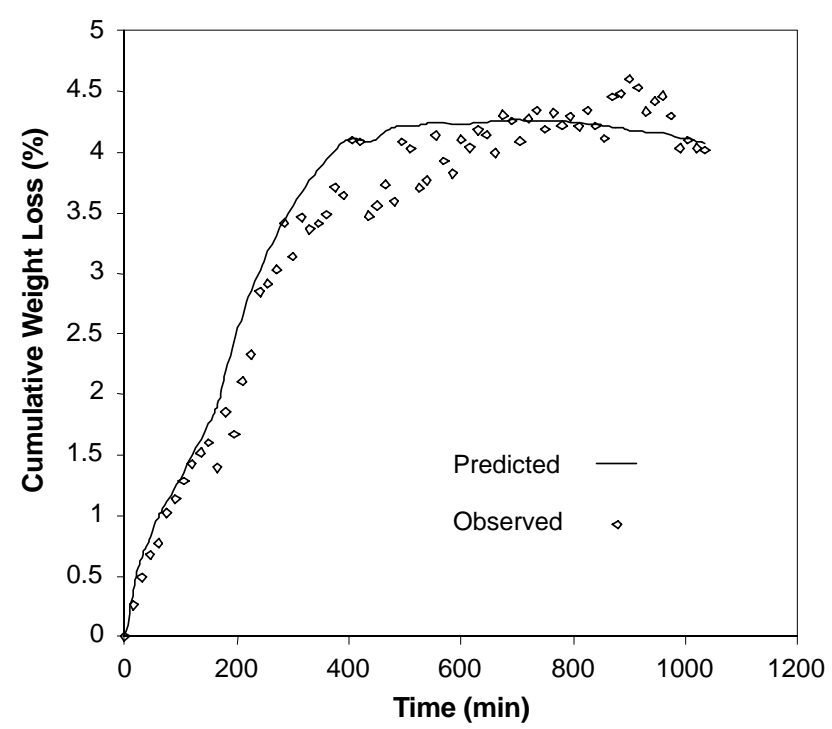

Figure 8. Comparison of observed and predicted weight loss history for validation test 1 (see table 2 for description of validation tests). of uncertainty may have had an effect on the model performance, mainly variations in product shape, thermocouple placement errors, and operating conditions of the chilling room. However, in practical terms, the maximum deviation obtained for center temperature can be considered low, which renders the model useful for general food safety applications.

\section{Applications of the Model in Food Safety Critical Parameters for Compliance with FSIS Stabilization Performance Standards}

Considering the difficulties that small meat processors face in complying with FSIS stabilization performance standards, the validated model was used to simulate different cooling scenarios. The purpose of these simulations was to establish critical processing conditions for both cured and non-cured cooked meats in small processing facilities (i.e., critical product sizes and environmental conditions in the chilling room at which compliance with FSIS stabilization requirements becomes physically impossible).

A total of 48 cooling scenarios were simulated for combinations of the following variables:

- Ham dimensions: three different sizes, representing typical commercially available products (7.07, 4.54, and $2.25 \mathrm{~kg}$ ).

- Air velocity: four velocity values, covering the range normally found in commercial air chilling rooms in small meat-processing facilities $(0.2,2.0,4.0$, and $6.0 \mathrm{~m} / \mathrm{s})$.

- Air temperature: four temperature regimes were explored. In three cases, constant air temperature values were considered $\left(-2^{\circ} \mathrm{C}, 0^{\circ} \mathrm{C}\right.$, and $\left.3^{\circ} \mathrm{C}\right)$. The fourth air temperature regime had a time-varying behavior, starting at an initial value of $33^{\circ} \mathrm{C}$ and then decreasing exponentially for $400 \mathrm{~min}$ until it reached a hypothetical setpoint value of $3^{\circ} \mathrm{C}$, after which it remained constant at that value (in real processing conditions, the temperature varies in a sinusoidal fashion around the setpoint). A similar situation was observed in commercial air chilling operations (fig. 7). 
Table 4. Deviations between predicted and observed temperature and weight loss histories for each validation test.

\begin{tabular}{|c|c|c|c|c|}
\hline \multirow[b]{2}{*}{$\begin{array}{l}\text { Validation } \\
\text { Test }\end{array}$} & \multirow[b]{2}{*}{$\begin{array}{c}\text { Location } \\
\text { within Ham }\end{array}$} & \multirow[b]{2}{*}{$n^{\prime}[\mathrm{a}]$} & \multicolumn{2}{|c|}{$M P^{[\mathrm{b}]}$} \\
\hline & & & $\begin{array}{c}\text { Temp. } \\
\left({ }^{\circ} \mathrm{C}\right)\end{array}$ & $\begin{array}{c}\text { Cumulative } \\
\text { Weight Loss } \\
(\%)\end{array}$ \\
\hline \multirow[t]{3}{*}{1} & Center & 2074 & 0.61 & 0.29 \\
\hline & $5.08 \mathrm{~cm}$ from center & 2074 & 0.84 & \\
\hline & Surface & 2074 & 1.99 & \\
\hline \multirow[t]{3}{*}{2} & Center & 2113 & 0.67 & 0.11 \\
\hline & $5.08 \mathrm{~cm}$ from center & 2113 & 1.06 & \\
\hline & Surface & 2113 & 0.94 & \\
\hline \multirow[t]{3}{*}{3} & Center & 2204 & 0.39 & 0.15 \\
\hline & $5.08 \mathrm{~cm}$ from center & 2204 & 1.19 & \\
\hline & Surface & 2204 & 1.55 & \\
\hline \multirow[t]{3}{*}{4} & Center & 2366 & 1.49 & 0.26 \\
\hline & $5.08 \mathrm{~cm}$ from center & 2366 & 2.20 & \\
\hline & Surface & 2366 & 2.24 & \\
\hline \multirow[t]{3}{*}{5} & Center & 1721 & 1.17 & 0.16 \\
\hline & $5.08 \mathrm{~cm}$ from center & 1721 & 1.20 & \\
\hline & Surface & 1721 & 0.89 & \\
\hline \multirow[t]{3}{*}{6} & Center & 1642 & 1.59 & 0.20 \\
\hline & $5.08 \mathrm{~cm}$ from center & 1642 & 1.28 & \\
\hline & Surface & 1642 & 2.54 & \\
\hline
\end{tabular}

[a] $n^{\prime}=$ number of observations compared for each validation.

[b] $M P=$ measure of model performance analogous to the root mean square error (see eq. 20).

- Relative humidity: this parameter was fixed at a constant value of $98 \%$ based on observations at commercial operations.

In all simulations, the initial center temperature was assumed to be $66^{\circ} \mathrm{C}$, with a typical initial temperature distribution as illustrated in figure 4 . Simulation results were organized into three distinct time periods to evaluate compliance with FSIS stabilization performance standards as: (1) time from $54.4^{\circ} \mathrm{C}$ to $26.6^{\circ} \mathrm{C}$, (2) time from $26.6^{\circ} \mathrm{C}$ to $7.2^{\circ} \mathrm{C}$, and (3) time from $26.6^{\circ} \mathrm{C}$ to $4.4^{\circ} \mathrm{C}$. Periods (1) and (2) correspond to the cooling guidelines for cured products, and time periods (1) and (3) correspond to guidelines for non-cured products. Tables 5 and 6 present the simulation time results pertinent to cured and non-cured products, respectively.

As can be observed in table 5, cooling times for cured products were within the times set out by the FSIS compliance guidelines in all cases. The "worst possible case" presented in table 5 would be a $7.07 \mathrm{~kg}$ ham with an air velocity of $0.2 \mathrm{~m} / \mathrm{s}$ and variable air temperature regime. In this case, the time from $54.4^{\circ} \mathrm{C}$ to $26.6^{\circ} \mathrm{C}$ was predicted as $236 \mathrm{~min}(3.9 \mathrm{~h})$, and from $26.6^{\circ} \mathrm{C}$ to $7.2^{\circ} \mathrm{C}$ as $394 \mathrm{~min}(6.6 \mathrm{~h})$, for a total time of $630 \mathrm{~min}(10.5 \mathrm{~h})$. This means that, in general, small meat processors should be able to meet the stabilization requirements for cured products, even for products as large as $7.07 \mathrm{~kg}$, with low air velocities and variable temperature conditions.

Conversely, in the case of non-cured products, it can be observed in table 6 that for the 7.07 and $4.54 \mathrm{~kg}$ hams, the cooling process would be out of compliance for the period between $54.4^{\circ} \mathrm{C}$ and $26.6^{\circ} \mathrm{C}$ in all cases. However, for the $4.54 \mathrm{~kg}$ ham, the combination of maximum air velocity $(6 \mathrm{~m} / \mathrm{s})$ and minimum air temperature $\left(-2^{\circ} \mathrm{C}\right)$ resulted in a cooling time only 2 min above FSIS compliance guidelines in this period. Thus, for this product size, there might still be an opportunity to meet the stabilization requirements with minor processing modifications. For example, slightly reducing the product dimensions, arranging the products carefully inside the chilling room to allow suitable air circulation, or using chilled water (as opposed to tap water) for showering after the cooking process to lower product surface temperature rapidly and to a value close to the air temperature inside the chilling room.

Nevertheless, the simulation results showed that compliance with FSIS stabilization performance standards for non-cured products during the period from $26.6^{\circ} \mathrm{C}$ to $4.4^{\circ} \mathrm{C}$ seems to be physically feasible for the $4.54 \mathrm{~kg}$ ham (for all constant air temperature regimes), and even for the $7.07 \mathrm{~kg}$ ham when the air temperature was $-2{ }^{\circ} \mathrm{C}$ for all velocities (table 6).

The process for the $2.25 \mathrm{~kg}$ ham would meet the stabilization requirements regardless of the environmental conditions, except in the case of the variable air temperature regime. As illustrated in figure 7, typical air temperatures in chilling rooms found in small meat-processing facilities are far from constant, especially within the first 300 to $450 \mathrm{~min}$, in which the air temperature decreases gradually until it reaches the setpoint. Thus, in practical terms, even for small non-cured products (i.e., $2.25 \mathrm{~kg}$ ), processors must be careful to use good cooling practices in order to meet the stabilization requirements. These practices include, for instance, not overloading the chilling room with product, allowing enough space between racks for air circulation, and maintaining the refrigeration unit in good operating conditions. These practices would prevent air temperature from varying excessively during the first stages of cooling, thus ensuring compliance with FSIS stabilization performance standards.

It is important to note from the results presented in tables 5 and 6 that little reduction in cooling time was observed when air velocity was increased from 2 to $4 \mathrm{~m} / \mathrm{s}$ or from 4 to $6 \mathrm{~m} / \mathrm{s}$ for the same air temperature. Wang and Sun (2002b) reported that for air chilling of cooked meats, the effect of increasing air velocity on reduction of total cooling times became smaller as the velocity increased above $2 \mathrm{~m} / \mathrm{s}$. This is explained by the fact that product surface temperature rapidly approaches the value of the air temperature, and the cooling rate is controlled by conduction throughout the meat body. Thus, differences in cooling times, with respect to air velocities, are observed only during the first stages of cooling, until the product surface temperature reaches a value close to the air temperature.

\section{Cooling Deviations Modeling}

The simulation program also was used to assess the implications of potential deviations that might occur during cooling processes. For that purpose, hypothetical cases in which equipment failure or electrical outage occurs were simulated for various downtimes. For the simulations, a large $7.07 \mathrm{~kg}$ cured ham was selected as the model system. Time-varying cooling conditions, similar to those used in real processing situations, were used for definition of boundary conditions (fig. 7). In all simulations, the initial center temperature was assumed to be $66^{\circ} \mathrm{C}$, with a typical initial temperature distribution as illustrated in figure 4.

Two hypothetical deviations were evaluated. In the first scenario (case 1), the downtime period began when the ham core temperature reached $60^{\circ} \mathrm{C}$ (i.e., $108 \mathrm{~min}$ from the beginning of cooling). The simulated downtime was $1 \mathrm{~h}$, 
Table 5. Analysis of selected example cured elliptical meat product sizes undergoing air chilling at various air temperature and air velocity conditions for time to decrease product core temperature and compliance with FSIS stabilization performance standards.

\begin{tabular}{|c|c|c|c|c|c|c|c|c|}
\hline \multirow{2}{*}{$\begin{array}{c}\text { Weight } \\
(\mathrm{kg})\end{array}$} & \multirow{2}{*}{$\begin{array}{l}\text { Dimensions } \\
(\mathrm{cm})\end{array}$} & \multirow{2}{*}{$\begin{array}{c}u_{a} \\
(\mathrm{~m} / \mathrm{s})\end{array}$} & \multirow{2}{*}{$\begin{array}{c}T_{a} \\
\left({ }^{\circ} \mathrm{C}\right)\end{array}$} & \multicolumn{2}{|c|}{$54.4^{\circ} \mathrm{C}$ to $26.6^{\circ} \mathrm{C}$} & \multicolumn{2}{|c|}{$26.6^{\circ} \mathrm{C}$ to $7.2^{\circ} \mathrm{C}$} & \multirow{2}{*}{$\begin{array}{c}\text { Overall } \\
\text { Compliance }\end{array}$} \\
\hline & & & & Time (min) & Compliance & Time $(\min )$ & Compliance & \\
\hline \multirow[t]{16}{*}{7.07} & Major axis & 0.2 & -2 & 158 & Yes & 222 & Yes & Yes \\
\hline & 30.0 & & 0 & 163 & Yes & 242 & Yes & Yes \\
\hline & & & 3 & 170 & Yes & 284 & Yes & Yes \\
\hline & & & Variable ${ }^{[a]}$ & 236 & Yes & 394 & Yes & Yes \\
\hline & Minor axis & 2 & -2 & 140 & Yes & 198 & Yes & Yes \\
\hline & 20.0 & & 0 & 145 & Yes & 220 & Yes & Yes \\
\hline & & & 3 & 153 & Yes & 267 & Yes & Yes \\
\hline & & & Variable & 220 & Yes & 379 & Yes & Yes \\
\hline & & 4 & -2 & 135 & Yes & 193 & Yes & Yes \\
\hline & & & 0 & 140 & Yes & 215 & Yes & Yes \\
\hline & & & 3 & 148 & Yes & 265 & Yes & Yes \\
\hline & & & Variable & 216 & Yes & 375 & Yes & Yes \\
\hline & & 6 & -2 & 132 & Yes & 190 & Yes & Yes \\
\hline & & & 0 & 137 & Yes & 213 & Yes & Yes \\
\hline & & & 3 & 145 & Yes & 264 & Yes & Yes \\
\hline & & & Variable & 213 & Yes & 372 & Yes & Yes \\
\hline \multirow[t]{16}{*}{4.54} & Major axis & 0.2 & -2 & 113 & Yes & 160 & Yes & Yes \\
\hline & 27.0 & & 0 & 116 & Yes & 174 & Yes & Yes \\
\hline & & & 3 & 121 & Yes & 203 & Yes & Yes \\
\hline & & & Variable & 186 & Yes & 341 & Yes & Yes \\
\hline & Minor axis & 2 & -2 & 98 & Yes & 139 & Yes & Yes \\
\hline & 16.0 & & 0 & 101 & Yes & 153 & Yes & Yes \\
\hline & & & 3 & 107 & Yes & 186 & Yes & Yes \\
\hline & & & Variable & 173 & Yes & 324 & Yes & Yes \\
\hline & & 4 & -2 & 94 & Yes & 134 & Yes & Yes \\
\hline & & & 0 & 97 & Yes & 149 & Yes & Yes \\
\hline & & & 3 & 102 & Yes & 183 & Yes & Yes \\
\hline & & & Variable & 168 & Yes & 321 & Yes & Yes \\
\hline & & 6 & -2 & 92 & Yes & 131 & Yes & Yes \\
\hline & & & 0 & 95 & Yes & 147 & Yes & Yes \\
\hline & & & 3 & 100 & Yes & 182 & Yes & Yes \\
\hline & & & Variable & 166 & Yes & 320 & Yes & Yes \\
\hline \multirow[t]{16}{*}{2.25} & Major axis & 0.2 & -2 & 81 & Yes & 114 & Yes & Yes \\
\hline & 21.2 & & 0 & 83 & Yes & 123 & Yes & Yes \\
\hline & & & 3 & 87 & Yes & 142 & Yes & Yes \\
\hline & & & Variable & 146 & Yes & 301 & Yes & Yes \\
\hline & Minor axis & 2 & -2 & 70 & Yes & 98 & Yes & Yes \\
\hline & 13.9 & & 0 & 72 & Yes & 108 & Yes & Yes \\
\hline & & & 3 & 76 & Yes & 130 & Yes & Yes \\
\hline & & & Variable & 137 & Yes & 287 & Yes & Yes \\
\hline & & 4 & -2 & 67 & Yes & 94 & Yes & Yes \\
\hline & & & 0 & 69 & Yes & 105 & Yes & Yes \\
\hline & & & 3 & 73 & Yes & 128 & Yes & Yes \\
\hline & & & Variable & 134 & Yes & 285 & Yes & Yes \\
\hline & & 6 & -2 & 65 & Yes & 93 & Yes & Yes \\
\hline & & & 0 & 67 & Yes & 104 & Yes & Yes \\
\hline & & & 3 & 71 & Yes & 127 & Yes & Yes \\
\hline & & & Variable & 132 & Yes & 284 & Yes & Yes \\
\hline
\end{tabular}

[a] Variable air temperature, similar to the one presented in figure 6 (see text for explanation).

during which there was no air circulation $\left(u_{a}=0 \mathrm{~m} / \mathrm{s}\right)$, and the air temperature rose rapidly at a rate that was controlled by the mass average temperature of the ham (eq. 18). After $1 \mathrm{~h}$, air velocity returned to its initial value, and air temperature decreased gradually until it reached the setpoint $\left(3^{\circ} \mathrm{C}\right)$. The rate of increase of air temperature was estimated by performing an overall energy balance inside the chilling room. The energy balance considered the total masses of ham (going into the room) and air (circulating throughout the chamber), based on measurements taken in processing plant 1 used during validation studies.

In the second hypothetical situation (case 2), the downtime period also began at 108 min from beginning of cooling. However, in this case, a "worst-case scenario," in which the total downtime was $6 \mathrm{~h}$, was simulated. Again, the mass average temperature of the ham was used as the overall 
Table 6. Analysis of selected example non-cured elliptical meat product sizes undergoing air chilling at various air temperature and air velocity conditions for time to decrease product core temperature and compliance with FSIS stabilization performance standards.

\begin{tabular}{|c|c|c|c|c|c|c|c|c|}
\hline \multirow{2}{*}{$\begin{array}{l}\text { Weight } \\
(\mathrm{kg})\end{array}$} & \multirow{2}{*}{$\begin{array}{l}\text { Dimensions } \\
(\mathrm{cm})\end{array}$} & \multirow{2}{*}{$\begin{array}{c}u_{a} \\
(\mathrm{~m} / \mathrm{s})\end{array}$} & \multirow{2}{*}{$\begin{array}{c}T_{a} \\
\left({ }^{\circ} \mathrm{C}\right)\end{array}$} & \multicolumn{2}{|c|}{$54.4^{\circ} \mathrm{C}$ to $26.6^{\circ} \mathrm{C}$} & \multicolumn{2}{|c|}{$26.6^{\circ} \mathrm{C}$ to $4.4^{\circ} \mathrm{C}$} & \multirow{2}{*}{$\begin{array}{c}\text { Overall } \\
\text { Compliance }\end{array}$} \\
\hline & & & & Time (min) & Compliance & Time $(\min )$ & Compliance & \\
\hline \multirow[t]{16}{*}{7.07} & Major axis & 0.2 & -2 & 158 & No & 280 & Yes & No \\
\hline & 30.0 & & 0 & 163 & No & 310 & No & No \\
\hline & & & 3 & 170 & No & 380 & No & No \\
\hline & & & Variable $^{[\mathrm{a}]}$ & 236 & No & 489 & No & No \\
\hline & Minor axis & 2 & -2 & 140 & No & 253 & Yes & No \\
\hline & 20.0 & & 0 & 145 & No & 287 & Yes & No \\
\hline & & & 3 & 153 & No & 363 & No & No \\
\hline & & & Variable & 220 & No & 475 & No & No \\
\hline & & 4 & -2 & 135 & No & 247 & Yes & No \\
\hline & & & 0 & 140 & No & 283 & Yes & No \\
\hline & & & 3 & 148 & No & 360 & No & No \\
\hline & & & Variable & 216 & No & 471 & No & No \\
\hline & & 6 & -2 & 132 & No & 244 & Yes & No \\
\hline & & & 0 & 137 & No & 281 & Yes & No \\
\hline & & & 3 & 145 & No & 358 & No & No \\
\hline & & & Variable & 213 & No & 469 & No & No \\
\hline \multirow[t]{16}{*}{4.54} & Major axis & 0.2 & -2 & 113 & No & 201 & Yes & No \\
\hline & 27.0 & & 0 & 116 & No & 221 & Yes & No \\
\hline & & & 3 & 121 & No & 269 & Yes & No \\
\hline & & & Variable & 186 & No & 407 & No & No \\
\hline & Minor axis & 2 & -2 & 98 & No & 177 & Yes & No \\
\hline & 16.0 & & 0 & 101 & No & 200 & Yes & No \\
\hline & & & 3 & 107 & No & 258 & Yes & No \\
\hline & & & Variable & 173 & No & 393 & No & No \\
\hline & & 4 & -2 & 94 & No & 171 & Yes & No \\
\hline & & & 0 & 97 & No & 195 & Yes & No \\
\hline & & & 3 & 102 & No & 254 & Yes & No \\
\hline & & & Variable & 168 & No & 390 & No & No \\
\hline & & 6 & -2 & 92 & No & 168 & Yes & No \\
\hline & & & 0 & 95 & No & 194 & Yes & No \\
\hline & & & 3 & 100 & No & 252 & Yes & No \\
\hline & & & Variable & 166 & No & 388 & No & No \\
\hline \multirow[t]{16}{*}{2.25} & Major axis & 0.2 & -2 & 81 & Yes & 143 & Yes & Yes \\
\hline & 21.2 & & 0 & 83 & Yes & 157 & Yes & Yes \\
\hline & & & 3 & 87 & Yes & 187 & Yes & Yes \\
\hline & & & Variable & 146 & No & 348 & No & No \\
\hline & Minor axis & 2 & -2 & 70 & Yes & 125 & Yes & Yes \\
\hline & 13.9 & & 0 & 72 & Yes & 140 & Yes & Yes \\
\hline & & & 3 & 76 & Yes & 178 & Yes & Yes \\
\hline & & & Variable & 137 & No & 334 & No & No \\
\hline & & 4 & -2 & 67 & Yes & 121 & Yes & Yes \\
\hline & & & 0 & 69 & Yes & 137 & Yes & Yes \\
\hline & & & 3 & 73 & Yes & 174 & Yes & Yes \\
\hline & & & Variable & 134 & No & 331 & No & No \\
\hline & & 6 & -2 & 65 & Yes & 119 & Yes & Yes \\
\hline & & & 0 & 67 & Yes & 136 & Yes & Yes \\
\hline & & & 3 & 71 & Yes & 173 & Yes & Yes \\
\hline & & & Variable & 132 & No & 329 & No & No \\
\hline
\end{tabular}

[a] Variable air temperature, similar to the one presented in figure 6 (see text for explanation).

reference value to control the maximum value that the air temperature would reach during the downtime.

Figures 9 and 10 illustrate the discussed deviations. In both figures, a product center temperature history following exactly the FSIS compliance guidelines for cured products (i.e., $5 \mathrm{~h}$ from $54.4^{\circ} \mathrm{C}$ to $26.6^{\circ} \mathrm{C}$, and $10 \mathrm{~h}$ from $26.6^{\circ} \mathrm{C}$ to $7.2^{\circ} \mathrm{C}$ ) was plotted as reference curve. As can be observed in figure 9 , a downtime of $1 \mathrm{~h}$ (case 1) was enough to cause a deviation of $1.57 \mathrm{~h}$ during the $54.4^{\circ} \mathrm{C}$ to $26.6^{\circ} \mathrm{C}$ period, and of $3.16 \mathrm{~h}$ during the $26.6^{\circ} \mathrm{C}$ to $7.2^{\circ} \mathrm{C}$ period, for a total of $4.73 \mathrm{~h}$ above FSIS compliance guidelines. Considering that minimal cooling occurred during the $1 \mathrm{~h}$ downtime, it was expected to have a drastic effect on cooling time. This was caused by the large cooling load associated with the total mass and the specific heat of product inside the chilling room. Specific heat values of cooked meats are approximately 


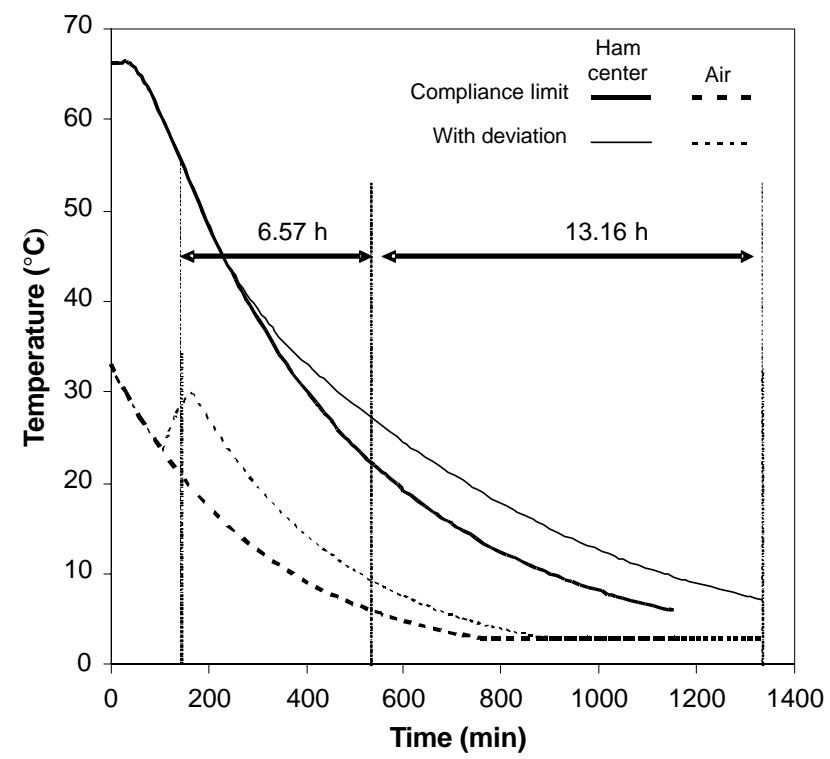

Figure 9. Effect of a hypothetical cooling deviation (case 1) on the temperature history of cooked ham during air chilling. The process is out of compliance by $1.57 \mathrm{~h}$ during the period from $54.4^{\circ} \mathrm{C}$ to $26.6^{\circ} \mathrm{C}$ and by $3.16 \mathrm{~h}$ during the period from $26.6^{\circ} \mathrm{C}$ to $7.2^{\circ} \mathrm{C}$.

4 times that of cold air. Moreover, due to the low value of air density, the total mass of air inside a chilling room can be considered negligible compared to that of cooked product. The resulting effect, from a simple energy balance, was a rapid increase in air temperature, even for a minor failure in refrigeration equipment or an electrical power outage.

Figure 10 shows the effect of the "worst case scenario" simulated in case 2 . As previously discussed, the cooling load of cooked product inside a chilling room caused air temperature to increase rapidly. Since in this case the downtime was $6 \mathrm{~h}$, air temperature remained fairly constant after it reached a value that was controlled by the mass

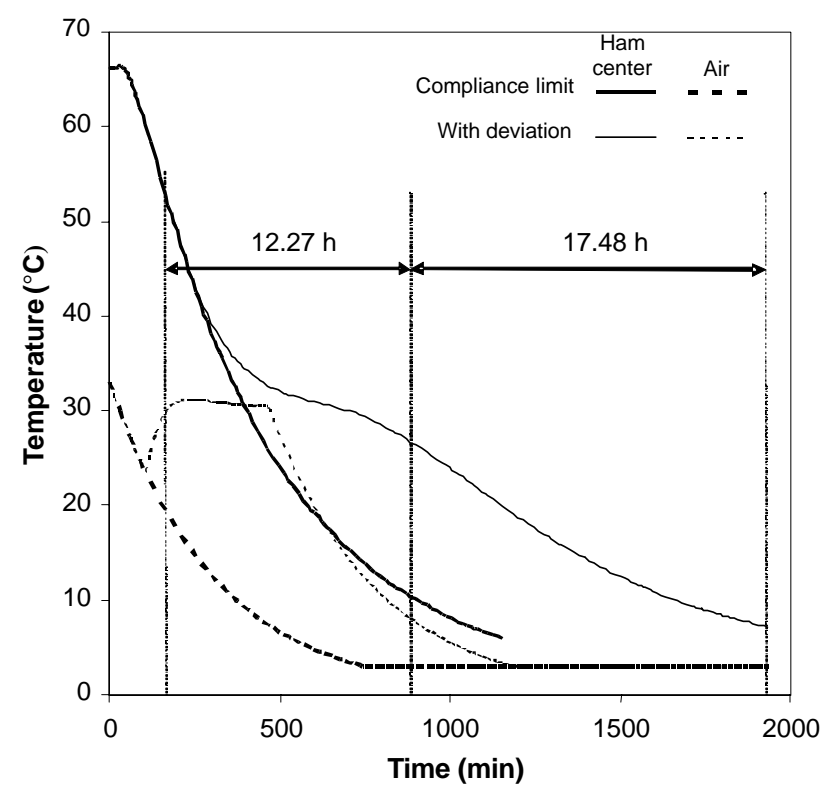

Figure 10. Effect of a hypothetical cooling deviation (case 2) on the temperature history of cooked ham during air chilling. The process is out of compliance by $7.27 \mathrm{~h}$ during the period from $54.4^{\circ} \mathrm{C}$ to $26.6^{\circ} \mathrm{C}$ and by $7.48 \mathrm{~h}$ during the period from $26.6^{\circ} \mathrm{C}$ to $7.2^{\circ} \mathrm{C}$. average temperature of cooked product. The resulting simulated cooling times were drastically above FSIS guidelines (fig. 10).

The information provided by such simulations would be tremendously beneficial in various food safety applications. For example, the predicted temperature histories resulting from a particular cooling scenario could be used as inputs for predictive dynamic $C$. perfringens growth models. Available computational tools such as the Pathogen Modeling Program (PMP) offered by the USDA (available at www.arserrc.gov/ $\mathrm{mfs} /$ pathogen.htm) allow the uploading of "csv" (commaseparated values) files that can be created readily in any spreadsheet software package. Thus, an accurately predicted temperature history obtained from the model presented in the current study could be uploaded for prediction of potential growth of surviving $C$. perfringens spores. PMP, however, only allows "csv" files of up to 50 rows; thus, it is limited to very big time steps, which could result in unrealistic C. perfringens growth predictions.

Therefore, it is still necessary to develop integrated models of heat transfer and dynamic microbial growth for accurate predictions of potential outgrowth of $C$. perfringens spores during cooling of large cooked meat products. Several modeling attempts have been reported (Huang, 2003; Juneja and Marks, 2002; Juneja et al., 2001; Juneja et al., 1999). However, these studies only emphasized the microbial part of the model, and overlooked the heat transfer problems by using simple hypothetical exponential product temperature histories. Effective integration of heat transfer and microbial modeling is a void that remains to be filled.

\section{Conclusions}

A two-dimensional transient heat conduction model for prediction of temperature and weight loss histories of large RTE meat products undergoing air chilling was developed and validated in this study. Predictions agreed well with experimental data collected in actual processing conditions. Maximum deviations between predicted and observed data were $2.54^{\circ} \mathrm{C}$ and $0.29 \%$ for temperature and cumulative weight loss, respectively.

Use of the model to assess the effect of different cooling scenarios for cured products showed that it was physically possible to meet FSIS stabilization performance standards in any reasonable situation found in small-meat processing facilities. However, for non-cured products, compliance with the standards depended on the time required for products to drop from $54.4^{\circ} \mathrm{C}$ to $26.6^{\circ} \mathrm{C}$. Under constant air temperature and air velocity regimes (the lowest air velocity and the highest air temperature values evaluated were $0.2 \mathrm{~m} / \mathrm{s}$ and $3^{\circ} \mathrm{C}$, respectively), cooling of a $2.25 \mathrm{~kg}$ non-cured product met the stabilization requirements in all cooling scenarios. However, under realistic time-varying air temperature conditions, the cooling process was not compliant for all velocity values (ranging from 0.2 to $6 \mathrm{~m} / \mathrm{s}$ ). Moreover, for larger non-cured products (i.e., 4.54 and $7.07 \mathrm{~kg}$ products), compliance was not physically possible for any combination of air temperature and air velocity.

Use of the model to assess the effect of an unexpected loss of process control (i.e., minor failure in refrigeration capacity) on cooling time of large RTE meat products showed large deviations from the FSIS standards. A simulated 
downtime of $1 \mathrm{~h}$ (starting at $1.8 \mathrm{~h}$ from the beginning of cooling) during the cooling of a $7.07 \mathrm{~kg}$ ham resulted in violating the FSIS compliance guidelines by $4.73 \mathrm{~h}$.

The model developed can be used to provide accurate product temperature histories under any typical set of cooling conditions and product sizes. In turn, the temperature values can be used as inputs for predictive microbial models. Implicit with this approach would be the accurate modeling of dynamic growth of microorganisms, such as $C$. perfringens, under time-varying temperature conditions including highly variable conditions caused by process deviations. Further development of quantitative tools such the heat transfer model presented integrated with dynamic microbial growth models is needed for regulatory agencies and personnel involved in food processing all over the world.

\section{ACKNOWLEDGEMENTS}

A contribution of the University of Nebraska Agricultural Research Division, Lincoln, Nebraska, Journal Series No. 14584. This research was supported in part by funds provided by the USDA-CSREES Integrated Research, Education, and Extension Competitive Grants Program - National Food Safety Initiative and through the Hatch Act.

\section{REFERENCES}

Amézquita, A. 2004. Development of an integrated model for heat transfer and dynamic growth of Clostridium perfringens during the cooling of cooked boneless ham. PhD diss. Lincoln, Neb.: University of Nebraska-Lincoln, Department of Biological Systems Engineering.

Arce, J., and V. E. Sweat. 1980. Survey of published heat transfer coefficients encountered in food refrigeration processes. ASHRAE Trans. 86(2): 235-260.

ASTM. 2003. E1269-01: Standard test method for determining specific heat capacity by differential scanning calorimetry. In Annual Book of ASTM Standards, 14.02: 380-385. West Conshohocken, Pa.: ASTM.

Choi, Y., and M. R. Okos. 1986. Effects of temperature and composition on the thermal properties of foods. In Food Engineering and Process Applications, 93-101. M. Le Maguer and P. Jelen, eds. New York, N.Y.: Elsevier Science.

Chuntranuluck, S., C. M. Wells, and A. C. Cleland. 1998a. Prediction of chilling times of foods in situations where evaporative cooling is significant - Part 1. Method development. J. Food Eng. 37(2): 111-125.

Chuntranuluck, S., C. M. Wells, and A. C. Cleland. 1998b. Prediction of chilling times of foods in situations where evaporative cooling is significant - Part 2. Experimental testing. J. Food Eng. 37(2): 127-141.

Chuntranuluck, S., C. M. Wells, and A. C. Cleland. 1998c. Prediction of chilling times of foods in situations where evaporative cooling is significant - Part 3. Applications. J. Food Eng. 37(2): 143-157.

Churchill, S. W. 1977. A comprehensive correlating equation for laminar, assisting, forced, and free convection. AIChE J. 23(1): $10-16$.

Daudin, J. D., and M. V. L. Swain. 1990. Heat and mass transfer in chilling and storage of meat. J. Food Eng. 12(2): 95-115.

Davey, L. M., and Q. T. Pham. 1997. Predicting the dynamic product heat load and weight loss during beef chilling using a multi-region finite difference approach. Int. J. Refrig. 20(7): 470-482.

Draper, N. R., and H. Smith. 1998. Applied Regression Analysis. New York, N.Y.: John Wiley and Sons.
Fontana, A. J., B. Wacker, C. S. Campbell, and G. S. Campbell. 2001. Simultaneous thermal conductivity, thermal resistivity, and thermal diffusivity measurement of selected foods and soils. ASAE Paper No. 016101. St. Joseph, Mich.: ASAE.

FSIS. 2002. Subpart D - Cured meats, unsmoked and smoked. Code of Federal Regulations, 9 CFR, Ch. III. 319: 299-300.

Geankoplis, C. J. 2003. Transport Processes and Separation Processes Principles (Includes Unit Operations). Upper Saddle River, N.J.: Prentice Hall.

Haghighi, K., and L. J. Segerlind. 1988. Modeling simultaneous heat and mass transfer in an isotropic sphere - A finite element approach. Trans. ASAE 31(2): 629-637.

Huang, L. 2003. Dynamic computer simulation of Clostridium perfringens growth in cooked ground beef. Int. J. Food Microbiol. 87(3): 217-227.

Jaluria, Y., and K. E. Torrance. 2003. Computational Heat Transfer. New York, N.Y.: Taylor and Francis.

Juneja, V. K., and H. M. Marks. 2002. Predictive model for growth of Clostridium perfringens during cooling of cooked cured chicken. Food Microbiol. 19(4): 313-327.

Juneja, V. K., J. S. Novak, H. M. Marks, and D. E. Gombas. 2001. Growth of Clostridium perfringens from spore inocula in cooked cured beef: Development of a predictive model. Innov. Food Sci. Emerg. Tech. 2(4): 289-301.

Juneja, V. K., R. C. Whiting, H. M. Marks, and O. P. Snyder. 1999. Predictive model for growth of Clostridium perfringens at temperatures applicable to cooling of cooked meat. Food Microbiol. 16(4): 335-349.

Kays, W. M., and M. E. Crawford. 1993. Convective Heat and Mass Transfer. New York, N.Y.: McGraw-Hill.

Kondjoyan, A., and J. D. Daudin. 1997. Heat and mass transfer coefficients at the surface of a pork hindquarter. J. Food Eng. 32(2): 225-240.

Kuitche, A., J. D. Daudin, and G. Letang. 1996a. Modelling of temperature and weight loss kinetics during meat chilling for time-variable conditions using an analytical-based method - I. The model and its sensitivity to certain parameters. J. Food Eng. 28(1): 55-84.

Kuitche, A., G. Letang, and J. D. Daudin. 1996b. Modelling of temperature and weight loss kinetics during meat chilling for time-variable conditions using an analytical-based method - II. Calculations versus measurements on wet plaster cylinders and cast. J. Food Eng. 28(1): 85-107.

Mallikarjunan, P., and G. S. Mittal. 1994. Heat and mass transfer during beef carcass chilling - Modelling and simulation. J. Food Eng. 23(3): 277-292.

Mallikarjunan, P., and G. S. Mittal. 1995. Optimum conditions for beef carcass chilling. Meat Sci. 39(2): 215-223.

Mallikarjunan, P., and G. S. Mittal. 1996. Selection criteria for beef carcass chilling. Food Res. Int. 29(7): 661-666.

Millsap, S. C., and B. P. Marks. 2002. Modeling condensing/convective heat transfer to food products in moist air impingement ovens. ASAE Paper No. 026045. St. Joseph, Mich.: ASAE.

Moyers, C. G., and G. W. Baldwin. 1997. Psychrometry, evaporative cooling, and solids drying. In Perry's Chemical Engineering Handbook, Ch. 12. R. H. Perry, D. W. Green, and J. O. Maloney, eds. New York, N.Y.: McGraw-Hill.

Murakami, E. G., V. E. Sweat, S. K. Sastry, E. Kolbe, K. Hayakawa, and A. Datta. 1996. Recommended design parameters for thermal conductivity probes for nonfrozen food materials. $J$. Food Eng. 27(2): 109-123.

Nolan, E. J. 1986. Chilling time estimates for cooked roast beef when using a liquid coolant. Fleischwirtschaft 66(11): $1625-1626$.

Nolan, E. J. 1987. Calculation of an approximate cooling curve for cooked roast beef. J. Food Proc. Eng. 9(4): 247-263.

Rahman, S. 1995. Food Properties Handbook. Boca Raton, Fla.: CRC Press. 
Reddy, J. N., and D. K. Gartling. 1994. The Finite Element Method in Heat Transfer and Fluid Dynamics. Boca Raton, Fla.: CRC Press.

Ryland, K. A., A. Amézquita, L. Wang, and C. L. Weller. 2004. Estimation of convective heat transfer coefficients of cooked boneless ham during air chilling. ASAE Paper No. MC04402. St. Joseph, Mich.: ASAE.

Segerlind, L. J. 1984. Applied Finite Element Analysis. New York, N.Y.: John Wiley and Sons.

Sweat, V. E., and C. G. Haugh. 1974. A thermal conductivity probe for small food samples. Trans. ASAE 17(1): 56-58.

Treybal, R. E. 1980. Mass-Transfer Operations. New York, N.Y.: McGraw-Hill.

USDA. 1999. Performance standards for the production of certain meat and poultry products. Final rule. Federal Register 64(3): 732-749.

Van Ness, H. C., and M. M. Abbott. 1997. Thermodynamics. In Perry's Chemical Engineering Handbook, Ch. 4. R. H. Perry, D. W. Green, and J. O. Maloney, eds. New York, N.Y.:

McGraw-Hill.

Wang, L., and D. W. Sun. 2002a. Evaluation of performance of slow air, air blast, and water immersion cooling in the cooked meat industry by the finite element method. J. Food Eng. 51(4): 329-340.

Wang, L., and D. W. Sun. 2002b. Modelling three conventional cooling processes of cooked meat by finite element method. Int. J. Refrig. 25(1): 100-110.

Wang, L., and D. W. Sun. 2002c. Modelling three-dimensional transient heat transfer of roasted meat during air blast by the finite element method. J. Food Eng. 51(4): 319-328.

Yovanovich, M. M. 1987a. New Nusselt and Sherwood numbers for arbitrary isopotential geometries at near zero Peclet and Rayleigh numbers. In AIAA 22nd Thermophysics Conference, Paper No. 871643. Reston, Va.: AIAA.

Yovanovich, M. M. 1987b. On the effect of shape, aspect ratio, and orientation upon natural convection from isothermal bodies of complex shape. In ASME Winter Annual Meeting, 121. New York, N.Y.: ASME.

Yovanovich, M. M. 1988. General expression for forced convection heat and mass transfer from isopotential spheroids. In AIAA 26th Aerospace Sciences Meeting, Paper No. 880743. Reston, Va.: AIAA.

\section{NOMENCLATURE}

$a \quad=$ major semi-axis of the ellipsoidal body (m)

$a_{w}=$ water activity at the product surface

$A=\operatorname{area}\left(\mathrm{m}^{2}\right)$

$b, d=$ minor semi-axes of the ellipsoidal body $(\mathrm{m})$

$B i=$ Biot number $\left(B i=h_{c} D / k\right)$

$c \quad=$ specific heat $(\mathrm{J} / \mathrm{kg} \mathrm{K})$

$D=$ characteristic dimension $(\mathrm{m})$

$D_{A B}=$ molecular diffusivity $\left(\mathrm{m}^{2} / \mathrm{s}\right)$

$e \quad=$ eccentricity of prolate spheroids $\left(e=\sqrt{1-(b / a)^{2}}\right)$

$\{F\}=$ global load vector

$g=$ acceleration due to gravity $\left(\mathrm{m} / \mathrm{s}^{2}\right)$

$G r=$ Grashof number $\left(G r=D^{3} \rho^{2} g \beta\left(T_{s}-T_{a}\right) / \mu^{2}\right)$

$h=$ heat transfer coefficient $\left(\mathrm{W} / \mathrm{m}^{2} \mathrm{~K}\right)$

$k=$ thermal conductivity $(\mathrm{W} / \mathrm{m} \mathrm{K})$

$k ”=$ mass transfer coefficient $\left(\mathrm{kg} / \mathrm{Pa} \mathrm{m}{ }^{2} \mathrm{~s}\right)$
$[K]=$ global stiffness matrix

$\mathrm{Le}=$ Lewis number $(\mathrm{Le}=\mathrm{Sc} / \mathrm{Pr})$

$m=$ mass $(\mathrm{kg})$

$[M]=$ global mass matrix

$n=$ total number of nodes

$n^{\prime}=$ total number of observations compared

$\{n\}=$ unit outward normal vector

$N$ = nodal shape function in the finite element formulation

$\{N\}=$ vector of nodal shape functions

$\mathrm{Nu}=$ Nusselt number $\left(\mathrm{Nu}=h_{c} \mathrm{D} / \mathrm{k}\right)$

$p \quad=$ partial pressure of water vapor in air $(\mathrm{Pa})$

$P_{\text {atm }}=$ atmospheric pressure $(\mathrm{Pa})$

$P r=$ Prandtl number $(\operatorname{Pr}=c \mu / k)$

$q "=$ heat flux $\left(\mathrm{W} / \mathrm{m}^{2}\right)$

$r \quad=$ radial distance coordinate $(\mathrm{m})$

$R=$ radial distance value at the surface $(\mathrm{m})$

$R a=$ Rayleigh number $(R a=G r \cdot P r)$

$R e=$ Reynolds number $(R e=\rho u D / \mu)$

$\mathrm{RH}=$ relative humidity

$S c=$ Schmidt number $\left(S c=\mu / \rho D_{A B}\right)$

$t \quad=$ time (s)

$T=$ temperature $\left({ }^{\circ} \mathrm{C}\right)$

$\{T\}=$ vector of nodal temperatures $\left({ }^{\circ} \mathrm{C}\right)$

$u=$ air velocity $(\mathrm{m} / \mathrm{s})$

$V \quad=$ volume $\left(\mathrm{m}^{3}\right)$

$z \quad=$ axial distance coordinate $(\mathrm{m})$

$Z \quad=$ axial distance value at the surface $(\mathrm{m})$

\section{GREEK LETTERS}

$\alpha=$ thermal diffusivity $\left(\mathrm{m}^{2} / \mathrm{s}\right)$

$\beta=$ volumetric coefficient of thermal expansion $(1 / \mathrm{K})$

$\varepsilon=$ emissivity

$\phi=$ angular distance coordinate $(\mathrm{m})$

$\lambda=$ latent heat $(\mathrm{J} / \mathrm{kg})$

$\mu=\operatorname{viscosity}(\mathrm{Pa} \mathrm{s})$

$\theta=$ parameter for time approximation schemes in equation 17 ( $\theta$ method)

$\rho=$ density $\left(\mathrm{kg} / \mathrm{m}^{3}\right)$

$\sigma=$ Stefan-Boltzman constant $\left(5.676 \times 10^{-8} \mathrm{~W} / \mathrm{m}^{2} \mathrm{~K}^{4}\right)$

\section{SUPERSCRIPTS}

$e=$ element

\section{SUBSCRIPTS}

0 = initial value

$a=$ ambient or air

alum = aluminum

$c \quad=$ convection

$f_{c} \quad=$ forced convection

$i, j, k=$ element node numbering

$K=$ absolute temperature in Kelvin

$n c=$ natural convection

$r \quad=$ radiation

$s=$ surface

$v \quad=$ evaporation

$w \quad=$ water 
